\title{
Airborne Bacteria in Earth's Lower Stratosphere Resemble Taxa Detected in the Troposphere: Results From a New NASA Aircraft Bioaerosol Collector (ABC)
}

David J. Smith ${ }^{1 *}$, Jayamary Divya Ravichandar ${ }^{2}$, Sunit Jain ${ }^{2}$, Dale W. Griffin ${ }^{3}$, Hongbin Yu ${ }^{4}$, Qian Tan ${ }^{5}$, James Thissen ${ }^{6}$, Terry Lusby ${ }^{1}$, Patrick Nicoll ${ }^{7}$, Sarah Shedler ${ }^{8}$, Paul Martinez ${ }^{9}$, Alejandro Osorio ${ }^{10}$, Jason Lechniak ${ }^{9}$, Samuel Choi ${ }^{10}$, Kayleen Sabino ${ }^{2}$, Kathryn Iverson ${ }^{2}$, Luisa Chan ${ }^{2}$, Crystal Jaing ${ }^{6}$ and John McGrath ${ }^{9}$

OPEN ACCESS

Edited by:

Pierre Amato,

UMR6296 Institut de Chimie de Clermont-Ferrand (ICCF), France

Reviewed by:

Noelle C. Bryan,

Massachusetts Institute of Technology, United States

Christopher E. Carr, Massachusetts Institute of Technology, United States

${ }^{*}$ Correspondence: David J. Smith david.j.smith-3@nasa.gov

Specialty section:

This article was submitted to Extreme Microbiology, a section of the journal

Frontiers in Microbiology

Received: 27 April 2018

Accepted: 13 July 2018

Published: 14 August 2018

Citation:

Smith DJ, Ravichandar JD, Jain S, Griffin DW, Yu H, Tan Q, Thissen J,

Lusby T, Nicoll P, Shedler S, Martinez P, Osorio A, Lechniak J, Choi S, Sabino K, Iverson K, Chan L,

Jaing C and McGrath J (2018) Airborne Bacteria in Earth's Lower

Stratosphere Resemble Taxa Detected in the Troposphere: Results From a New NASA Aircraft Bioaerosol

Collector (ABC).

Front. Microbiol. 9:1752.

doi: 10.3389/fmicb.2018.01752
${ }^{1}$ NASA Ames Research Center, Space Biosciences Division, Moffett Field, CA, United States, ${ }^{2}$ Second Genome Inc., South San Francisco, CA, United States, ${ }^{3}$ United States Geological Survey, Environmental Health, St. Petersburg, FL,

United States, ${ }^{4}$ Climate and Radiation Laboratory, NASA Goddard Space Flight Center, Greenbelt, MD, United States,

${ }^{5}$ Earth Science Division, Bay Area Environmental Research Institute, Moffett Field, CA, United States, ${ }^{6}$ Lawrence Livermore National Laboratory, Livermore, CA, United States, ${ }^{7}$ Space Biosciences Division, Blue Marble Space Institute of Science, Moffett Field, CA, United States, ${ }^{8}$ Biological Oceanography Department, University of South Florida, College of Marine Sciences, St. Petersburg, FL, United States, ${ }^{9}$ NASA Armstrong Flight Research Center, Palmdale, CA, United States,

${ }^{10}$ Jacobs Technology Inc., NASA Armstrong Flight Research Center, Palmdale, CA, United States

Airborne microorganisms in the upper troposphere and lower stratosphere remain elusive due to a lack of reliable sample collection systems. To address this problem, we designed, installed, and flight-validated a novel Aircraft Bioaerosol Collector (ABC) for NASA's C-20A that can make collections for microbiological research investigations up to altitudes of $13.7 \mathrm{~km}$. Herein we report results from the first set of science flights-four consecutive missions flown over the United States (US) from 30 October to 2 November, 2017. To ascertain how the concentration of airborne bacteria changed across the tropopause, we collected air during aircraft Ascent/Descent (0.3 to $11 \mathrm{~km})$, as well as sustained Cruise altitudes in the lower stratosphere $(\sim 12 \mathrm{~km})$. Bioaerosols were captured on DNA-treated gelatinous filters inside a cascade air sampler, then analyzed with molecular and culture-based characterization. Several viable bacterial isolates were recovered from flight altitudes, including Bacillus sp., Micrococcus sp., Arthrobacter sp., and Staphylococcus sp. from Cruise samples and Brachybacterium sp. from Ascent/Descent samples. Using 16S V4 sequencing methods for a culture-independent analysis of bacteria, the average number of total OTUs was 305 for Cruise samples and 276 for Ascent/Descent samples. Some taxa were more abundant in the flight samples than the ground samples, including OTUs from families Lachnospiraceae, Ruminococcaceae and Erysipelotrichaceae as well as the following genera: Clostridium, Mogibacterium, Corynebacterium, Bacteroides, Prevotella, Pseudomonas, and Parabacteroides. Surprisingly, our results revealed a homogeneous distribution of bacteria in the atmosphere up to $12 \mathrm{~km}$. The observation could be due to atmospheric conditions producing similar background aerosols across the western US, as suggested by modeled back trajectories and satellite measurements. 
However, the influence of aircraft-associated bacterial contaminants could not be fully eliminated and that background signal was reported throughout our dataset. Considering the tremendous engineering challenge of collecting biomass at extreme altitudes where contamination from flight hardware remains an ever-present issue, we note the utility of using the stratosphere as a proving ground for planned life detection missions across the solar system.

Keywords: bioaerosols, bacteria, C-20A, troposphere, stratosphere, Aircraft Bioaerosol Collector (ABC)

\section{INTRODUCTION}

Microbial "highways" flow naturally overhead in Earth's atmosphere (Schmale and Ross, 2015) but "traffic patterns" elude the international aerobiology research community due to a widespread shortage of sampling opportunities. Although airborne biomass eventually returns to the surface, low sedimentation rates of microorganisms allows potentially long periods aloft in the upper atmosphere and, consequently, long distances traveled downwind (Bovallius et al., 2006; Reche et al., 2018). A variety of ground and airborne studies have recently reported that viable microorganisms can be delivered across continents and oceans (Prospero et al., 2005; Bowers et al., 2011; Toepfer et al., 2011; Favet et al., 2012; Smith et al., 2012, 2013; Yamaguchi et al., 2012; Barberán et al., 2015; Tang et al., 2016; Gat et al., 2017; Maki et al., 2017; Weil et al., 2017), microbes at lower altitudes in clouds might be temporarily active (Klein et al., 2016; Amato et al., 2017c), biomass (intact cells, spores, or debris) can influence cloud chemistry and precipitation patterns (Deguillaume et al., 2008; Bowers et al., 2009; Vaïtilingom et al., 2010, 2013; Amato et al., 2015), and biosignatures can still be detected up to $38 \mathrm{~km}$ (Smith, 2013). Since all marine and surface environments are impacted by winds, the emanation/deposition of airborne microorganisms (hereafter referred to as bioaerosols) contributes to ecosystem dynamics. For instance, airborne microorganisms surviving harsh conditions while aloft, including strong levels of mutagenic ultraviolet radiation, might be altered at the genomic, transcriptomic, and proteomic level upon germination in a new environment (Smith et al., 2011; Chudobova et al., 2015; Waters et al., 2015; Khodadad et al., 2017). With hundreds of teragrams of microbe-laden dusts from deserts and agricultural soils moving through Earth's atmosphere each year (Acosta-Martinez et al., 2015), additional surveys are needed to better understand the ecological consequences of airborne biomass exchange, including disease dispersal (Brown and Hovmoller, 2002; Fröhlich-Nowoisky et al., 2016; Mahaffee and Stoll, 2016; Van Leuken et al., 2016). Ultimately, more sampling opportunities above the boundary layer (i.e., $>2 \mathrm{~km}$ above the Earth's surface) will improve long range modeling efforts aimed at providing predictive tools for aerobiology studies at regional and global scales (Burrows et al., 2009a,b; Griffin et al., 2017).

Before future investigations addressing the origin, destination, survival, and mutation of airborne microorganisms can be realistically implemented, routine and reliable access to the upper atmosphere for collecting bioaerosols must first be established. High-altitude aircraft are a compelling choice for capturing airborne microorganisms considering the multitude of government and commercially operated platforms flying into the upper atmosphere every day. Ride-along sample collections on aircraft would enable transformative opportunities for the aerobiology research community by providing substantial spatiotemporal coverage. Despite an abundance of aircraft worldwide, surprisingly few studies have attempted in-flight collections of bioaerosols, perhaps because no standard hardware package exists for sample acquisition. Detailed engineering schematics and discussions of contamination control techniques onboard aircraft are notably absent in the small group of aircraft-based aerobiology literature (Meier and Lindbergh, 1935; Polunin and Kelly, 1952; Timmons et al., 1966; Trägårdh, 1977; Borodulin et al., 2005; Hill et al., 2007; DeLeonRodriguez et al., 2013; Maki et al., 2013). As the sensitivity and affordability of molecular methods in microbiology improves each year, so should a general awareness that hardware used for aerobiology surveys can be highly susceptible to contaminants (Smith and Griffin, 2013; Griffin et al., 2017). In the era of molecular assays, the aerobiology research community must adopt stricter quality control procedures-reporting detailed hardware designs, contamination control approaches and monitoring methods-similar to standard practices in space exploration (e.g., life detection and planetary protection) (Vaishampayan et al., 2013; Benardini et al., 2014; Summons et al., 2014) and industry (e.g., pharamceutical manufacuturing facilities). Improvements evaluating contamination have been recently made in studies using high altitude balloons (Bryan et al., 2014) but such stringency has not yet been implemented with aircraft experiments.

Accordingly, the primary aim of our study was to develop a low cost, reproducible window-mounted aircraft hardware system (Figure 1A) for microbiology collections in the upper troposphere and lower stratosphere. Our new system, the Aircraft Bioaerosol Collector (ABC), was designed to (1) function at extreme altitude and high aircraft velocities; (2) capture free stream atmospheric air samples at subzero temperatures; (3) regulate air flow (on/off) for collections at specific altitudes of interest; (4) use DNA-treated collection filters, replaceable in flight; (5) size separate bioaerosols; and (6) have components that could be easily installed, removed and periodically cleaned. After building and installing the ABC, we flew 4 test flights over the continental USA at altitudes up to $12.2 \mathrm{~km}$ demonstrating its operability. We sampled above and below the lower stratosphere to test the hypothesis that the tropopause serves as Earth's 
naturally occurring altitudinal biosphere boundary; specifically, we expected a significant drop in bioaerosol abundance and richness in the lower stratosphere $(\sim 12 \mathrm{~km})$ compared to the troposphere $(0.3$ to $12 \mathrm{~km})$. To evaluate our hypothesis we characterized airborne bacteria using molecular and culturebased methods, and we determined the atmospheric transport history of sampled air using meteorological models and satellite data.

\section{MATERIALS AND METHODS}

\section{Aircraft Description}

NASA's C-20A Gulfstream III aircraft is available through the Airborne Science Program at Armstrong Flight Research Center (AFRC). The aircraft can reach altitudes of $13.7 \mathrm{~km}$ and cover a range of $6.3 \mathrm{~km}$ with an air speed up to $237 \mathrm{~m} \cdot \mathrm{s}^{-1}$. Flights can last $5-7 \mathrm{~h}$ and carry about $1,000 \mathrm{~kg}$ of useful scientific payload. During the course of our study, C-20A ride-along flight opportunities were provided by AFRC and the Uninhabited Aerial Vehicle Synthetic Aperture Radar (UAVSAR) team from NASA Jet Propulsion Laboratory (Koo et al., 2012). We flew 4 research flights across regions of the western USA: Eel River (Science Flight \#955); California San Andreas Fault (CSAF) (Science Flight \#956); Slumgullion (Science Flight \#957); and LA
Basin (Science Flight \#958). Each flight path remained above the state of California (CA) except for the Slumgullion flight that also crossed over Arizona, Nevada, Utah, and Colorado.

\section{Aircraft Bioaerosol Collector (ABC)}

Sampling free stream air (King, 1984) was an essential system design feature. The atmospheric probe (Figure 1B) was a miniaturized version of larger pitot-style inlets used on the NASA DC-8 aircraft for collecting atmospheric aerosols $<4 \mu \mathrm{m}$ (Talbot et al., 1998; Dibb et al., 1999; Scheuer et al., 2003). STAR-CCM+ modeling (Siemens PLM Software, Plano, TX) and aerodynamic calculations were performed to determine a position for the probe that would pass through free stream air uninfluenced by $\mathrm{C}$ $20 \mathrm{~A}$ engines or surfaces. We built a custom $29 \mathrm{~cm}(l) \times 16 \mathrm{~cm}(w)$ $\mathrm{x} 3 \mathrm{~cm}(h)$ probe from aluminum (AL7050-T7452 per AMS 4050) with an inner diameter of $0.3 \mathrm{~cm}$ and clam shell construction that was secured with 6 screws (NAS11530-9), sealed using AMS-S-8802 sealant, and anodized (MIL-A-8625 type II). When mounted, the probe mass was $\sim 1 \mathrm{~kg}$ and it was positioned $16 \mathrm{~cm}$ from the window plate, angled at 1.5 degrees below horizontal.

Depicted in Figure 1C, the probe-captured air traveled through hose lines (Part \# 101001-3CR-0240; 101001-3CR-0065; 101001-3CR-0064; 101003-3CR-0360, Aviall Hose Shop, Van Nuys, CA) and into a sterilized 2-stage cascade sampler (Product
A

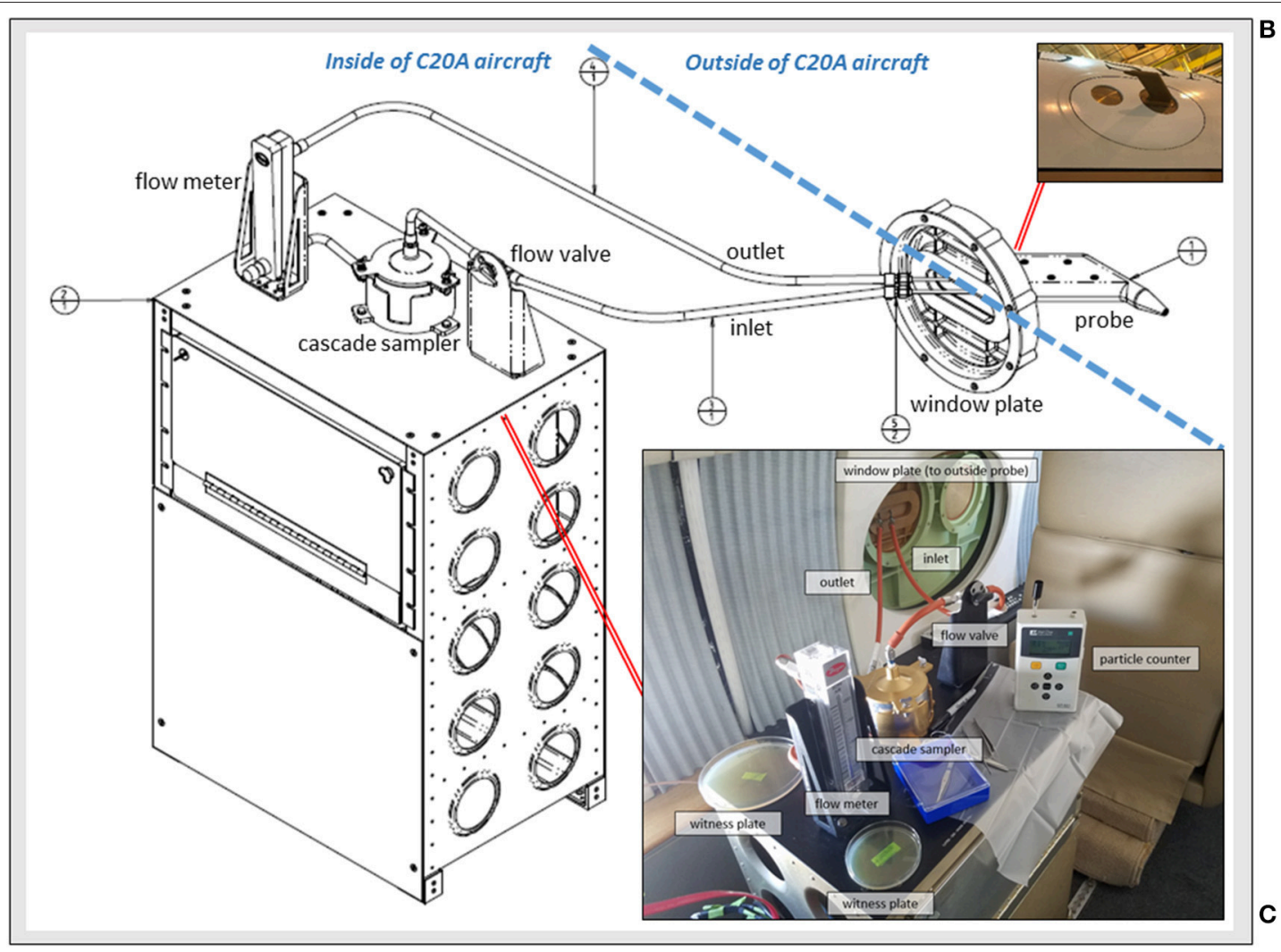

FIGURE 1 | The Aircraft Bioaerosol Collector (ABC) system on the NASA C-20A aircraft. (A) Engineering diagram for components inside and outside of the aircraft; (B) Photograph of the window plate mounted probe for capturing free stream air; and (C) View from inside of the C-20A during in-flight operations with system elements labeled. 
\# TE-10-860; Tisch Environmental, Cleves, $\mathrm{OH}$ ) with successive aluminum stages fastened together by a butterfly cap and clamp system with silicone o-rings for air-tight sealing (039S70 and 044S70). The cascade sampler sat on a custom-built workbench containing all system components and supplies needed for flight operations. We modified the top portion of the sampler with quick release fasteners to allow for filter replacement in flight. Each sampler stage had 400 small round drilled orifices $(1.18 \mathrm{~mm}$ on first stage; $0.25 \mathrm{~mm}$ on second stage). Gamma-irradiated (i.e., DNA-treated) gelatinous filter membranes (Part \#16799-100102500, Sartorius, Bohemia, NY) sat underneath each aluminum stage for bioaerosol capture. Each filter was supported by a manufacturer-provided grid of polyethylene that was cut down to size and sterilized before use with a $90 \%$ isopropyl alcohol rinse (Sigma-Aldrich, St. Louis, MO). Plating the sterilized support grids on R2A (Difco, Sparks, MD) media did not yield any bacterial growth after 1 week of incubation at $25^{\circ} \mathrm{C}$. Once atmospheric air traveled across the cascade sampler stages and gelatinous filter membranes, it then passed through a volumetric flow meter (Model RMC, Dwyer, Michigan City, IN). Flow rates were monitored during each flight and averaged $8.51 \cdot \mathrm{min}^{-1}$ at the aircraft's cruise altitude of $\sim 12 \mathrm{~km}$. After passing the flow meter, air traveled into an exhaust line and back out the window port. To prevent air flow during take-off or landing, a ball valve (Part \# 2F-B2LJ2-SSP-LD, Valin, San Jose, CA) was installed in-line and upstream of the cascade sampler.

\section{Experimental Design and Sample Description}

Table 1 summarizes the collections in our study and Figure 2 shows photographs of the sample locations. Prior to flying, accessible $\mathrm{ABC}$ components and tools were sterilized by autoclaving or with isopropyl alcohol rinses. The window plate and probe inlet were assayed for contaminants using a pre-wetted sterile applicator (part \# 25-8062WC, Puritan, Guilford, ME) before the C-20A departed the aircraft hangar; these samples were Hardware controls. Swabs were stored in $5 \mathrm{ml}$ of sterile deionized water within a $15 \mathrm{ml}$ Falcon tube and kept at $4^{\circ} \mathrm{C}$ until laboratory

TABLE 1 | Summary of samples.

\begin{tabular}{|c|c|c|c|c|c|c|c|}
\hline & $\begin{array}{l}\text { Date } \\
(2017)\end{array}$ & Flight & Type & $\begin{array}{l}\text { Time } \\
\text { (min) }\end{array}$ & CFUs & PCR Yield $\left(\mathrm{ng} \cdot \mu \mathrm{I}^{-1}\right)$ & Notes \\
\hline 1 & 30 Oct & Eel River & Ground & - & 4 & 20.99 & Ground, pre-flight, side of aircraft \\
\hline 2 & 30 Oct & Eel River & Ground & - & 1 & 20.99 & Ground, post-flight, side of aircraft \\
\hline 3 & 30 Oct & Eel River & Atmosphere & 42 & 1 & 12.82 & Ascent/Descent, in-flight, top stage of sampler \\
\hline 4 & 30 Oct & Eel River & Atmosphere & 42 & 0 & 20.11 & Ascent/Descent, in-flight, bottom stage of sampler \\
\hline 5 & 30 Oct & Eel River & Atmosphere & 141 & 0 & 20.66 & Cruise, in-flight, top stage of sampler \\
\hline 6 & 30 Oct & Eel River & Atmosphere & 141 & 0 & 20.99 & Cruise, in-flight, bottom stage of sampler \\
\hline 7 & 31 Oct & CSAF & Ground & - & 7 & 20.99 & Ground, pre-flight, side of aircraft \\
\hline 8 & 31 Oct & CSAF & Ground & - & 7 & 14.22 & Ground, post-flight, side of aircraft \\
\hline 9 & 31 Oct & CSAF & Atmosphere & 41 & 0 & 3.43 & Ascent/Descent, in-flight, top stage of sampler \\
\hline 10 & 31 Oct & CSAF & Atmosphere & 41 & 1 & 0.01 & Ascent/Descent, in-flight, bottom stage of sampler \\
\hline 11 & 31 Oct & CSAF & Atmosphere & 250 & 0 & 0.28 & Cruise, in-flight, top stage of sampler \\
\hline 12 & 31 Oct & CSAF & Atmosphere & 250 & 0 & 0.86 & Cruise, in-flight, bottom stage of sampler \\
\hline 13 & 1 Nov & Slumgullion & Ground & - & 0 & 3.31 & Ground, pre-flight, side of aircraft \\
\hline 14 & 1 Nov & Slumgullion & Ground & - & 0 & 2.82 & Ground, post-flight, side of aircraft \\
\hline 15 & $1 \mathrm{Nov}$ & Slumgullion & Atmosphere & 43 & 0 & 9.88 & Ascent/Descent, in-flight, top stage of sampler \\
\hline 16 & $1 \mathrm{Nov}$ & Slumgullion & Atmosphere & 43 & 0 & 8.59 & Ascent/Descent, in-flight, bottom stage of sampler \\
\hline 17 & 1 Nov & Slumgullion & Atmosphere & 240 & 6 & 8.05 & Cruise, in-flight, top stage of sampler \\
\hline 18 & $1 \mathrm{Nov}$ & Slumgullion & Atmosphere & 240 & 0 & 8.1 & Cruise, in-flight, bottom stage of sampler \\
\hline 19 & $2 \mathrm{Nov}$ & LA Basin & Ground & - & 2 & 18.13 & Ground, pre-flight, side of aircraft \\
\hline 20 & $2 \mathrm{Nov}$ & LA Basin & Ground & - & 0 & 19.62 & Ground, post-flight, side of aircraft \\
\hline 21 & $2 \mathrm{Nov}$ & LA Basin & Atmosphere & 52 & 0 & 11.63 & Ascent/Descent, in-flight, top stage of sampler \\
\hline 22 & $2 \mathrm{Nov}$ & LA Basin & Atmosphere & 52 & 0 & 20.4 & Ascent/Descent, in-flight, bottom stage of sampler \\
\hline 23 & $2 \mathrm{Nov}$ & LA Basin & Atmosphere & 181 & 0 & 1.11 & Cruise, in-flight, top stage of sampler \\
\hline 24 & $2 \mathrm{Nov}$ & LA Basin & Atmosphere & 181 & 0 & 11.75 & Cruise, in-flight, bottom stage of sampler \\
\hline 25 & $2 \mathrm{Nov}$ & LA Basin & Ground & - & 0 & 10.13 & Negative control, blank filter loaded into upper stage of sampler \\
\hline 26 & $2 \mathrm{Nov}$ & LA Basin & Ground & - & 0 & 8.24 & Negative control, blank filter loaded into lower stage of sampler \\
\hline 27 & 30 Oct & Eel River & Ground & - & 1 & 14.84 & Hardware, pre-flight, probe sample \\
\hline 28 & 30 Oct & Eel River & Ground & - & 0 & 20.99 & Hardware, pre-flight, window plate sample \\
\hline 29 & 30 Oct & Eel River & Ground & - & 0 & 19.24 & Hardware, post-flight, probe sample \\
\hline 30 & 30 Oct & Eel River & Ground & - & 2 & 11.8 & Hardware, post-flight, window plate sample \\
\hline
\end{tabular}




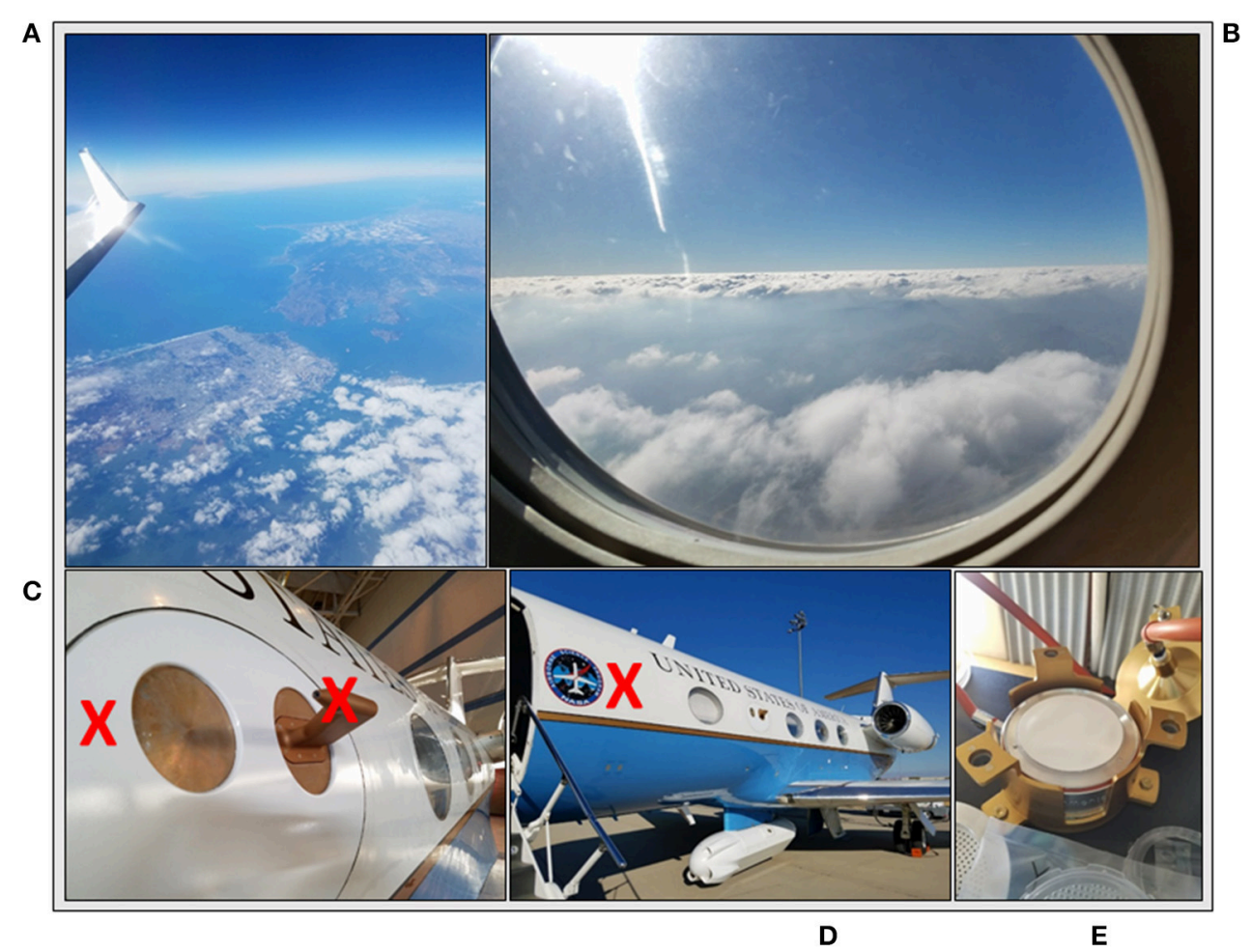

FIGURE 2 | Experimental design overview. (A) Cruise samples at $\sim 12 \mathrm{~km}$; (B) Ascent/Descent samples ranging from 0.3 to $12 \mathrm{~km}$; (C) Ground hardware samples (probe and window plate, red X indicating area swabbed); (D) Ground samples (side of aircraft, red X indicating area swabbed); and (E) Negative control sample where blank filter was loaded into cascade sampler.

processing. Following the swab assay, the probe inlet was rinsed with isopropyl alcohol and sprayed dry with sterile air canisters. Before take-off and after landing, an exterior portion of the C$20 \mathrm{~A}$ directly upstream of the probe was assayed using the swab method; these samples were Ground controls. The same area was sampled on consecutive days of flight operations to determine the bioburden of airborne microorganisms settling onto the C-20A during fueling, take-off and landing operations.

Each flight day, the C-20A departed from and returned to AFRC (Palmdale, CA). Free stream atmospheric air collection began $\sim 300 \mathrm{~m}$ above ground level after take-off by opening the $\mathrm{ABC}$ ball valve and flow meter. Upon reaching $10 \mathrm{~km}(\sim 10 \mathrm{~min}$ into each flight), air flow for Ascent samples was stopped and new filters for Cruise samples were aseptically loaded into the cascade sampler for collections at the sustained altitude of $\sim 12 \mathrm{~km}$ which lasted 141-250 min during the flight campaign. Two types of agarose witness plates (TSA and R2A, Remel, Fremont, CA) were installed on the workbench and exposed to ambient aircraft cabin air during flight operations to assess the amount of contamination inside the cabin air influencing filters during installation and removal procedures. A particle counter (Model GT-521, Met One Instruments, Inc., Grants Pass, OR) with 0.3 and $0.5 \mu \mathrm{m}$ counting channels measured on average 13,400 particles and 300 particles, respectively, in the aircraft cabin air. Used filters were stored inside sterile Whirl-Paks (Part \#B01297, Nasco, Modesto, CA) and kept inside an insulated cooler at $4^{\circ} \mathrm{C}$.
After the Cruise sample collection and prior to aircraft Descent below $10 \mathrm{~km}$, the Ascent sample filters were returned into the cascade sampler, combining the Ascent \& Descent samples for this study. The decision to pool Ascent/Descent samples (300$10 \mathrm{~km}$ ) was made in order to focus our analysis on the potential difference between bacterial concentration and diversity in the troposphere vs. lower stratosphere. Air flow into the ABC was stopped again at $\sim 300 \mathrm{~m}$ above ground level on runway approach for the C-20A at AFRC. Upon completion of each flight, cascade sampler components were cleaned with isopropyl alcohol; swabs and filters were kept at $4^{\circ} \mathrm{C}$ until transport back to NASA Ames (Moffett Field, CA).

\section{Microbiological Methods Sample Concentration}

Using sterile scissors and forceps, gelatinous filters were halved inside a Class II Type A Biosafety Cabinet (NU-540-600, Nuaire, Plymouth, MN). For each sample, one filter half was archived in a $-80^{\circ} \mathrm{C}$ freezer (TSU-600A, Thermo Scientific, Asheville, $\mathrm{NC})$ and the other half was dissolved in $40 \mathrm{ml}$ of warm $\left(37^{\circ} \mathrm{C}\right)$ molecular grade water (H2OMB0124, Millipore, Billerica, MA). Next, we used a concentrating pipette (CP Select, InnovaPrep, Drexel, MO) which passed the entire dissolved sample volume $(40 \mathrm{ml})$ through a $0.1 \mu \mathrm{m}$ flat membrane polyethersulfone membrane (part number CC08001), followed by elution with Tris buffer into a final output volume of $1 \mathrm{ml}$. Similarly, swabs 
contained in $15 \mathrm{ml}$ tubes (wetted with $5 \mathrm{ml}$ of sterile water) from Ground and Hardware control samples obtained from the window plate, probe, and side of the aircraft were concentrated in $1 \mathrm{ml}$ of Tris. For each concentrated volume, $800 \mu \mathrm{l}$ of was used for DNA extraction and subsequent 16S V4 sequencing; $100 \mu \mathrm{l}$ was used for culture-based recovery assays; and $100 \mu \mathrm{l}$ was archived at $-80^{\circ} \mathrm{C}$ in the freezer.

\section{Recovery of Viable Isolates and Identification}

Concentrated $100 \mu \mathrm{l}$ aliquots were evenly spread onto R2A to encourage the recovery of viable heterotrophic bacteria. All samples were wrapped with Parafilm (American National Can, Chicago, IL) and placed in a dark incubator (SHKE6000, MaxQ 6000, Thermo Scientific, Manetta, $\mathrm{OH}$ ) at $25^{\circ} \mathrm{C}$ for 2 weeks while monitoring for signs of growth. Table 1 summarizes the number of colony forming units (CFUs) for each sample. Individual colonies were sub-cultured on R2A until isolated and cryopreserved with $10 \%$ sterile glycerol (Amresco, Solon, $\mathrm{OH}$ ) and nutrient broth (Difco, Sparks, MD) at $-80^{\circ} \mathrm{C}$. Deoxyribonucleic acid (DNA) extraction was performed on each isolate, followed by the polymerase chain reaction (PCR) amplification of $16 \mathrm{~S}$ ribosomal ribonucleic acid (rRNA). A 466 bp 16S universal primer set from Nadkarni et al. (2002) [forward primer: $\quad 5^{\prime}$-TCCTACGGGAGGCAGCAGT-3' $\left(\mathrm{T}_{\mathrm{m}}, 59.4^{\circ} \mathrm{C}\right)$; reverse primer: $5^{\prime}$-GGACTACCAGGGTATCTAATCCTGTT-3' $\left.\left(\mathrm{T}_{\mathrm{m}}, 58.1^{\circ} \mathrm{C}\right)\right]$ was used to generate bacterial amplicons. Sequence data from GENEWIZ (South Planfield, NJ) were then mapped to the most probable taxonomic affiliation of the bacteria using the Basic Local Alignment Search Tool (BLAST) ${ }^{1}$.

\section{S V4 Sequencing}

DNA from each $800 \mu$ l concentrated sample aliquot was extracted using an AllPrep PowerViral DNA/RNA kit (product \# 28000-50, Qiagen) then quantified by the Quant-iT PicoGreen dsDNA Assay Kit (Invitrogen, Life Technologies, Grand Island, NY). PCR amplification of the V4 hypervariable region of the bacterial $16 \mathrm{~S}$ rDNA gene enriched samples prior to MiSeq (Illumina, San Diego, CA) sequencing. Post-amplification yields averaged $12.2 \mathrm{ng} \cdot \mu \mathrm{l}^{-1}$ across samples with the upper limit of the reaction at $20.99 \mathrm{ng} \cdot \mu \mathrm{l}^{-1}$ based on the ladders utilized. For library construction and normalization, we used two differently bar coded V4 fusion primers designed against the surrounding conserved regions tailed with sequences to incorporate Illumina adapters and indexing barcodes. Post amplification, each sample was quantified by fluorometric methods (Qubit or PicoGreen from Invitrogen, Life Technologies, Grand Island, NY) before sequencing. Every amplicon (containing 16S V4 enriched, amplified, barcoded samples) was loaded into a single MiSeq cartridge and flow cell for paired-end sequencing runs.

After sequencing, a bioinformatics analysis by Second Genome Inc. (South San Francisco, CA) filtered and trimmed all reads, followed by mapping to taxonomic databases for identifying bacterial composition. Detailed explanations for statistical methods, including quality control and assurance techniques, have been described elsewhere (Benjamini and

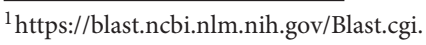

Hochberg, 1995; Anderson, 2001; Oksanen et al., 2010; McDonald et al., 2012; Edgar, 2013; McMurdie and Holmes, 2013, 2014; Love et al., 2014). Briefly, a custom software package pre-processed, summarized, and normalized data followed by calculations of alpha diversity metrics (within sample diversity), beta diversity metrics (sample-to-sample similarity), ordination/clustering, sample classification, and significance testing. Representative Operation Taxonomic Unit (OTU) sequences were assigned using mothur's bayesian classifier, with clusters referenced at $99 \%$ alignment to the Greengenes ${ }^{2}$ database of $16 \mathrm{~S}$ gene sequences. For additional information on reproducing the data pipeline we refer readers to Mohan et al. (2016), Alhasson et al. (2017), and Reveles et al. (2017). Access to raw sequencing data can be downloaded in the supporting files associated with this project archived at GeneLab ${ }^{3}$ using accession GLDS-170. To account for possible contaminants associated with the experimental design, filtered taxonomic tables were generated after removing a subset of OTUs identified from extractionnegative and no-template PCR control samples. Both raw and filtered OTU tables are available in the GLDS-170 project folder.

\section{Environmental Data and Atmospheric Modeling}

We collected GPS position, altitude, wind speed, aircraft speed, and air temperature data from the C-20A during flight operations. To understand the transport history of the air masses sampled, we calculated 2-day kinematic back-trajectories over the flight paths using the Hybrid Single-Particle Lagrangian Integrated Trajectory (HYSPLIT) model (Stein et al., 2015) which uses global meteorological data from the Global Data Assimilation System archive. Trajectories were run at 3 heights (300, 5,000, and $12,000 \mathrm{~m}$ above ground level). In order to gain $1 \mathrm{~km}$-scale resolution of the vertical distribution of aerosols and components (e.g., $\mathrm{SO}_{4}$, organic carbon, black carbon, dust, sea salt), we retrieved satellite data from MODIS and produced aerosol optical depth (AOD) maps at $470 \mathrm{~nm}$ based on the MAIAC retrieval algorithm (Lyapustin et al., 2011). These resulted in a 3-D model of aerosol distribution along flight lines (matching latitude, longitude, and altitude) using MERRA-2 methods (Gelaro et al., 2017).

\section{RESULTS}

\section{Flight Data and Atmospheric Modeling}

Pertinent flight data are summarized in Table 2. The modeled air mass back trajectories and aerosol distribution suggest our flights passed through air with similar transport histories and bulk aerosol composition. Figure 3 depicts the HYSPLIT model based on GDAS meteorological data at heights and positions within the range of C-20A flight lines. Generally, the 48-h back trajectories resemble each other across the modeled heights, showing air masses traveling eastward off the Pacific Ocean into the US. Mostly uniform aerosol mass loading was observed across the flight lines (Figure 4)

\footnotetext{
${ }^{2}$ http://greengenes.secondgenome.com/downloads

${ }^{3}$ https://genelab.nasa.gov/
} 
TABLE 2 | Environmental and positional data averaged across flights.

\begin{tabular}{|c|c|c|c|c|c|c|}
\hline Flight & Time (UTC) & Air Temp $\left({ }^{\circ} \mathrm{C}\right)$ & Altitude (km) & Air Speed $\left(m \cdot s^{-1}\right)$ & Wind Speed $\left(m \cdot s^{-1}\right)$ & Wind Direction $\left({ }^{\circ}\right)$ \\
\hline Eel River & $17: 16$ to $21: 07$ & -26.7 & 12.15 & 231.3 & 17.3 & 308.9 \\
\hline CSAF & $16: 48$ to $22: 10$ & -28.9 & 12.17 & 225.4 & 13.2 & 127.2 \\
\hline Slumgullion & $16: 14$ to $21: 18$ & -32.4 & 12.17 & 226.0 & 16.6 & 287.1 \\
\hline LA Basin & $17: 34$ to $23: 09$ & -27.6 & 12.06 & 226.3 & 22.8 & 236.9 \\
\hline
\end{tabular}
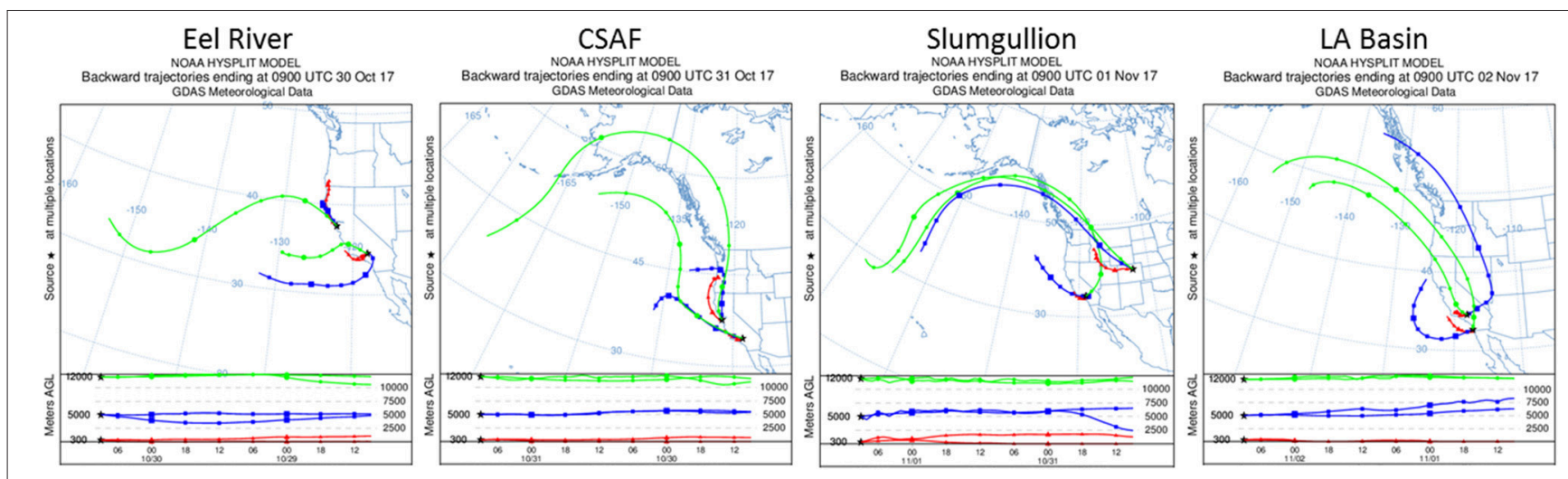

FIGURE 3 | HYSPLIT kinematic back trajectories model air transport history for flights 30 Oct to 2 Nov 2017.

with Aerosol Optical Depth (AOD) measurements at $470 \mathrm{~nm}$ using the MAIAC retrieval algorithm derived from combined satellite datasets (MODIS/Terra and MODIS/Aqua). Satellite observations of modeled aerosol concentrations at $\sim 12 \mathrm{~km}$ were higher during the Eel River (30 Oct 2017) and CSAF (31 Oct 2017) flights and lower on Slumgullion (1 Nov 2017) and LA Basin (2 Nov 2017) flights, consisting primarily of $\mathrm{SO}_{4}$, organic carbon, dust, black carbon, and sea salt (Figure 5). Satellite data also showed smoke influence near ground levels along the CSAF flight track. MERRA-2 aerosol simulations (Figures 6, 7) were produced using C-20A flight positions (latitude, longitude, and altitude) and were consistent with the MAIAC derived AOD distribution. MERRA-2 results show aerosol concentrations decreasing sharply with altitude (i.e., highest concentrations were in the lower atmosphere at Ascent/Descent). The concentration of aerosols was low $(<0.5$ $\mu \mathrm{g} \cdot \mathrm{m}^{-3}$ ) most of the flight time at Cruise altitudes of $\sim 12 \mathrm{~km}$. However, one exception at $12 \mathrm{~km}$ was the CSAF flight ( 31 Oct 2017) when the aerosol concentration briefly reached up to $10 \mu \mathrm{g} \cdot \mathrm{m}^{-3}$.

\section{Culture-Based Results}

Most of the culturable bacteria collected in the study came from (Ground) swabs of the exterior portion of the C$20 \mathrm{~A}$ before and after flights. Bacterial isolates included numerous Bacillus carboniphilus, B. crescens, B. fumarioli, B. megaterium, B. aryabhattai, B. humi, and B. timonesis, as well as Gordonia paraffinivorans, Bhargavaea ginseng, and Streptomyces sp. Bacillus timonesis was also obtained from a post-flight swab of the window plate where the ABC probe was mounted. Several bacterial isolates were recovered from in-flight collections, including Bacillus sp., Micrococcus sp., Arthrobacter sp., and Staphylococcus sp. from Cruise samples and Brachybacterium sp. from Ascent/Descent samples. However, none of the flight isolates were identifiable to the species level with Sanger sequencing of the 16S rRNA gene because of the relatively short region $(\sim 466 \mathrm{bp})$ covered by the assay.

Witness plates were used during each flight to monitor bacteria from C-20A cabin air settling onto the surface of the workbench. Although the ABC cascade sampler housed DNAtreated filters were sealed off from the cabin air during collection periods, filter change-out procedures exposed samples to cabin air for several minutes. Blank filters loaded did not yield any CFUs, however witness plates exposed to cabin air during the entire duration of flights ( $\sim 250 \mathrm{~min}$ on average) resulted in a substantial amount of culture-based growth. The mean number of bacterial and fungal CFUs collected on witness plates was 0.663 $\mathrm{CFU} \cdot \mathrm{cm}^{-2}$.

\section{Culture-Independent Results: 16S V4 Sequencing}

Altogether, 2,557 OTUs were observed from 3,911,495 sequences. Of the OTUs, $98.86 \%$ of sequences were classified at the family level; $95.11 \%$ at genus; $2.837 \%$ at species; and $2.38 \%$ at strain. Prevalence filtering was applied to remove any spurious OTUs that were observed in less than $5 \%$ of the samples. After removal of the spurious OTUs, the number of total OTUs was reduced from 2,557 to 1,181 and the number of total sequences dropped from $3,911,495$ to $3,886,523$. The number of reads in the filtered library for Ascent/Descent group ranged from 2,470 to $160,341(N=97,689)$; Cruise 

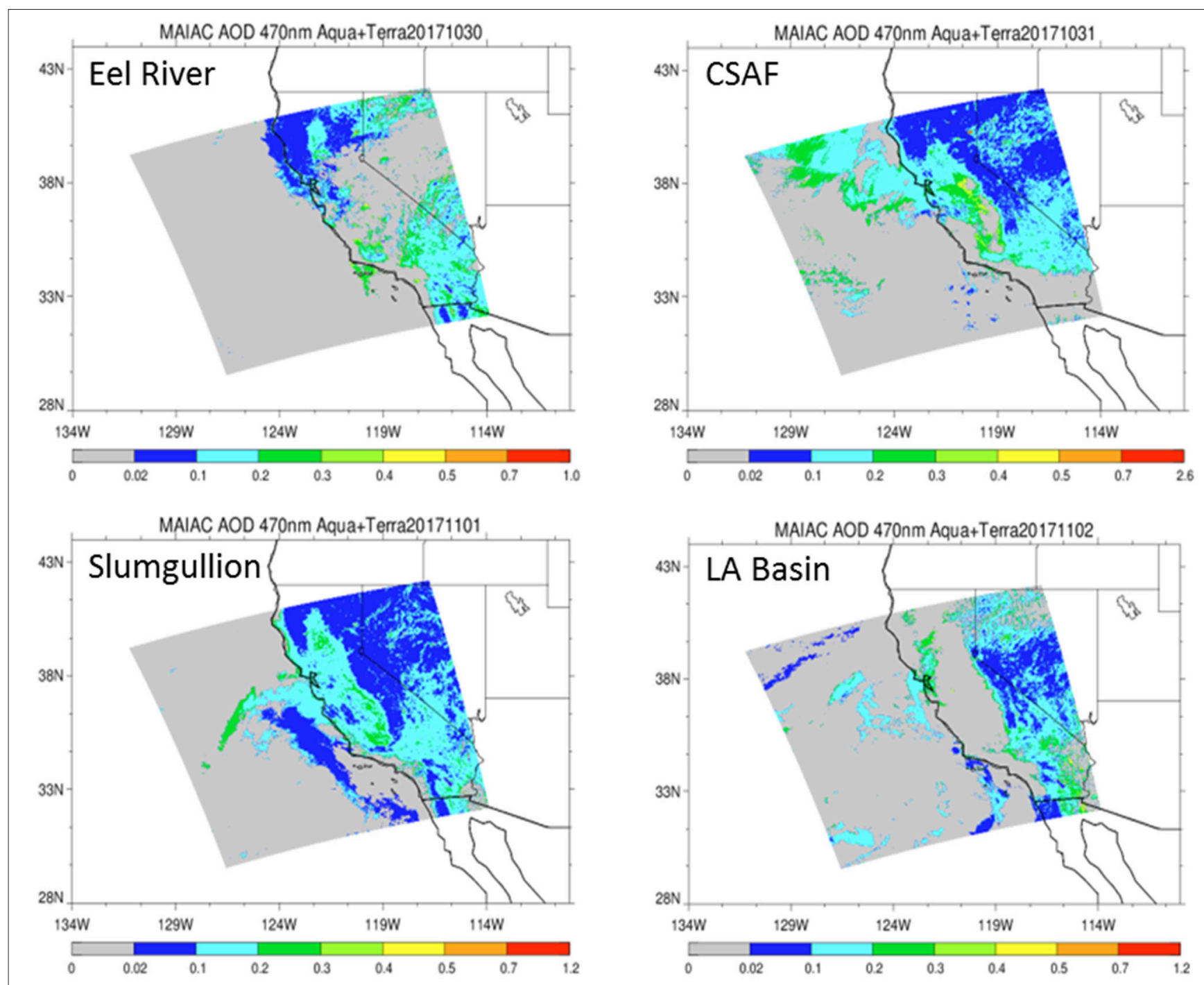

FIGURE 4 | Aerosol Optical Depth (AOD) measurements at $470 \mathrm{~nm}$ based on the MAIAC retrieval algorithm derived from combined satellite datasets (MODIS/Terra and MODIS/Aqua) shows vertically integrated aerosols over relevant flight lines.

group ranged from 12,693 to $707,558(N=188,541)$; Ground group ranged from 98,459 to $234,313(N=136,160)$; and Hardware group ranged from 108,177 to $147,995(N=133,094)$. After filtering, the number of unique categories at each taxonomic rank was 879 species, 609 genera, and 268 families.

Table 3 summarizes the eight most abundant phyla detected in the study (Firmicutes, Proteobacteria, Actinobacteria, Bacteroidetes, Cyanobacteria, an Unclassified phylum, Euryarchaeota, and Fusobacteria). Firmicutes and Proteobacteria, and to a lesser extent Actinobacteria, represent the majority of samples. Hardware samples had a slightly higher proportion of Proteobacteria and a lower abundance of Firmicutes compared to Ascent/Decent, Cruise, and Ground samples. The seven most abundant classes across all categories were Bacilli, Gammaproteobacteria,
Betaproteobacteria, Clostridia, Actinobacteria, Erysipelotrichi, and Alphaproteobacteria. The eight most abundant families detected from all samples were Staphylococcaceae, Moraxellaceae, Oxalobacteraceae, Lachnospiraceae, Ruminococcaceae, Comamonadaceae, Geodermatophilaceae, and Burkholderiaceae.

Figure 8 depicts the richness of samples by showing the number of unique OTUs and Shannon diversity indices across each category based on abundance data. Means for OTU richness were higher for Ground (449; sd = 94.5) and Hardware (407; sd $=56)$ samples than flight samples from Ascent/Descent $(276$; sd $=96.3)$ and Cruise $(305 ;$ sd $=107)$ altitudes. Table 4 summarizes the significant alpha diversity differences between groups using an unpaired Kruskal-Wallis test. There were significant differences between flight groups (Ascent/Descent and Cruise) compared to Ground and Hardware groups. Similar to the OTU richness results, Shannon diversity indices were 
also higher for Ground (1.53; sd $=0.523)$ and Hardware (1.93; sd $=0.421)$ samples compared to flight samples from Ascent/Descent (1.38; sd =0.296) and Cruise (1.26; sd =0.446).

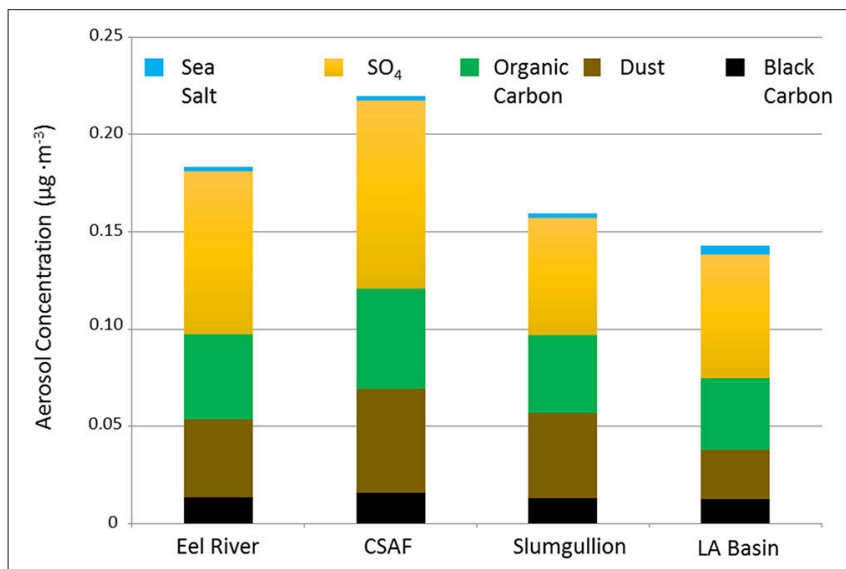

FIGURE 5 | MERRA-2 data summarizing $\mathrm{SO}_{4}$, organic carbon, dust, black carbon, and sea salt aerosol concentrations averaged across the cruise altitude of $\sim 12 \mathrm{~km}$ for each flight.
To visualize the relationship between sample groups (Cruise, Ascent/Descent, Ground, Hardware) and ascertain sample-to-sample dissimilarity based on whole microbiome abundance profiles, we used a Principal Coordinate Analysis (PCoA). While the weighted ordination in Figure 9 (based on relative abundance) did not show clustering or any significant differences by sample group with a PERMANOVA analysis using Bray-Curtis dissimilarity ( $p$-value $=0.081$ ), an unweighted ordination in Figure 10 (based on presence or absence) depicted non-significant but noticeable differences across groups using Jaccard distance ( $p$-value $=0.097$ ) Specifically, the Ground and Hardware samples clustered separately from the Ascent/Descent and Cruise samples. One possible explanation for the perceived separation could be the relative enrichment in OTUs from phylum Actinobacteria in Ground samples, compared to the enrichment in OTUs from phylum Firmicutes in Ascent/Descent and Cruise samples. Ten strains identified as significantly enriched (adjusted $p$ value $<0.05)$ in Ground samples compared to flight samples potentially contributed to the separation between groups: Blastococcus sp. BC412; Georgenia sp. JC82; Modestobacter multiseptatus; Modestobacter versicolor; Modestobacter marinus; Clostridium sordellii; Ornithinimicrobium kibberense;

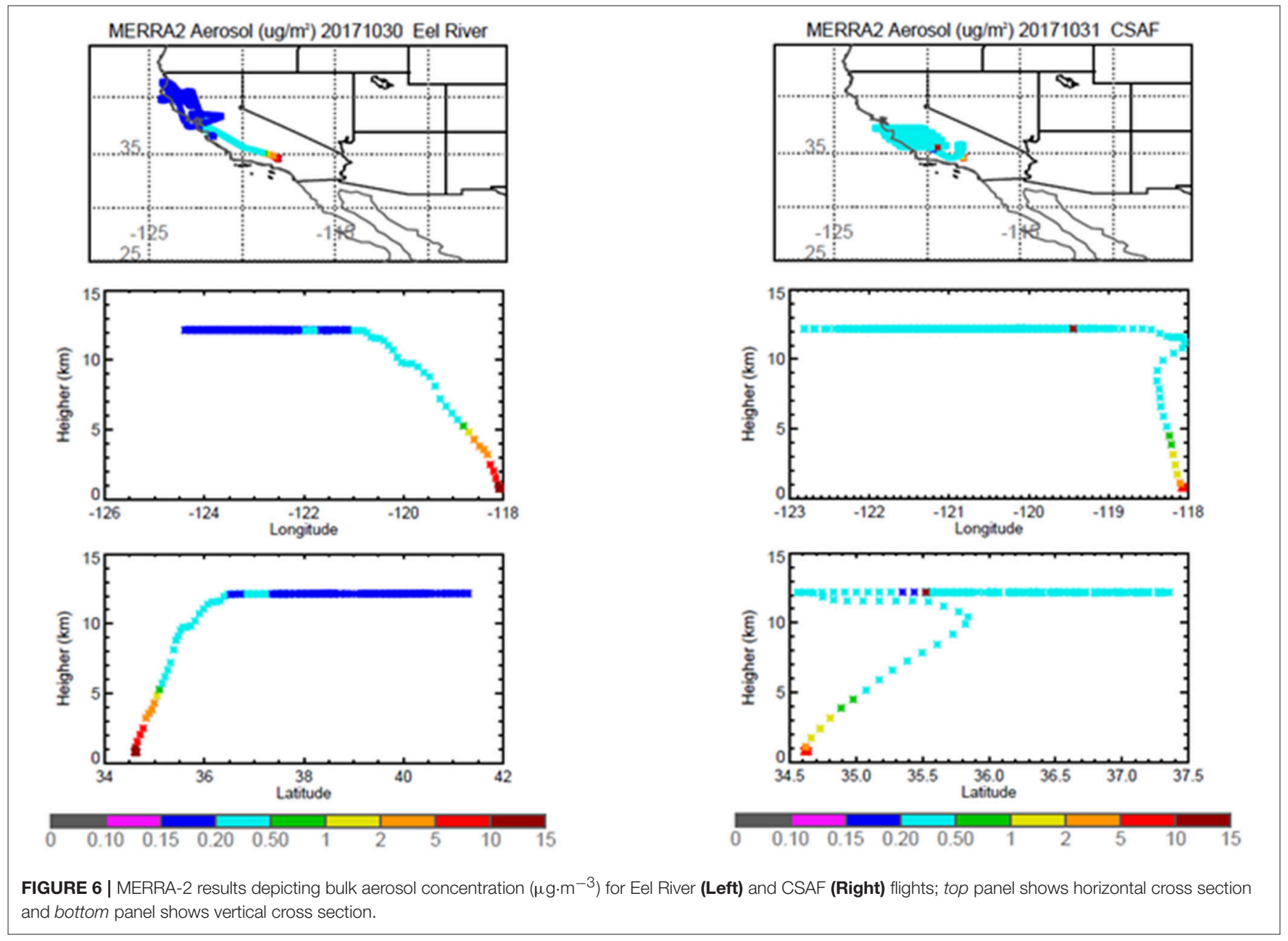




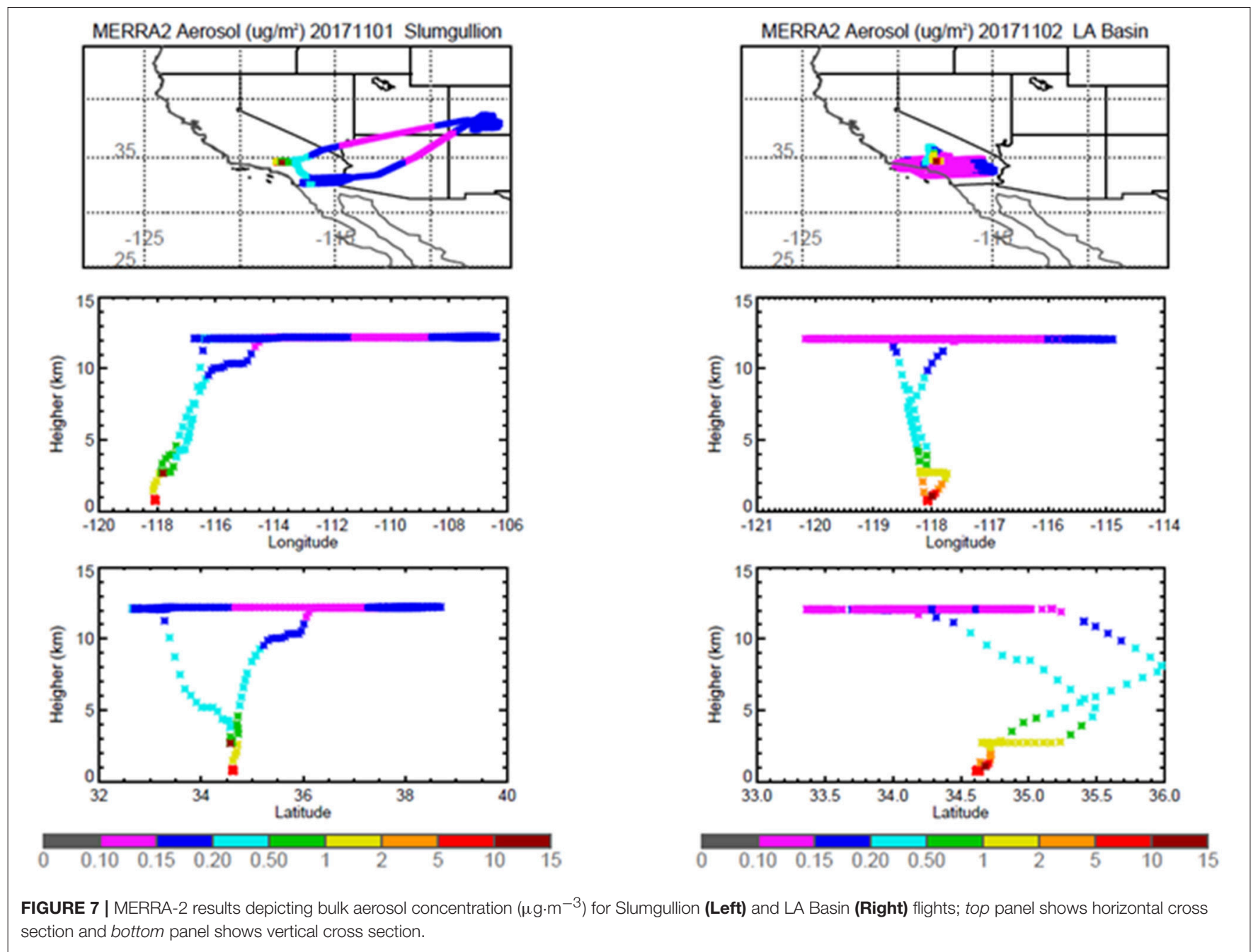

Yaniella sp. G5; Nocardioides sp. MSL 22; and Blastococcus jejuensis.

Because the ordination data showed Ascent/Descent samples and Cruise samples were more similar to each other than different, Figure 11 was generated to highlight which OTUs stood out from Ground samples. A total of 28 OTUs were found to be differentially abundant between Ground samples and Ascent/Descent samples. Notably, OTUs from the families Lachnospiraceae and Erysipelotrichaceae and the genera Clostridium, Mogibacterium, Bacteroides, Prevotella, and Parabacteroides were more abundant in the Ascent/Descent samples than the Ground samples. When comparing differentially abundant OTUs in Ground samples against Cruise samples, a total of 25 OTUs were identified. The taxa more abundant in Cruise samples included OTUs from the families Erysipelotrichaceae and Ruminococcaceae and the following genera: Clostridium, Mogibacterium, Corynebacterium, and Prevotella. Pseudomonas stutzeri was the only OTU identified at the species level that was significantly more abundant in Cruise samples than Ground samples.
In order to determine if the differing daily flight paths contributed to microbiome diversity, we performed a PERMANOVA analysis for testing significant differences between each set of flight samples. Despite significant differences based on PERMANOVA ( $p$-value $=0.013$ ), a weighted ordination plot in Figure 12 using abundance data showed that flight samples did not cluster according to flight location. Airborne bacteria collected over Eel River, CSAF, Slumgullion, and LA Basin were more similar than different. An unweighted ordination shown in Figure 13 using presence/absence data also showed no clear clustering by flight.

Finally, we analyzed samples on each of the two cascade sampler stages to ascertain if bacteria collected in the ABC were size sorted. The first stage of the sampler had $1.18 \mathrm{~mm}$ drilled orifices, the second stage had $0.25 \mathrm{~mm}$ drilled orifices. According to manufacturer specifications ${ }^{4}$, at ground-normal STP conditions using a flow rate of $28.3 \mathrm{~L} \cdot \mathrm{min}^{-1}$, the first stage would select for particles 5.8 to $9 \mu \mathrm{m}$ and the second stage 0.7 to $1.1 \mu \mathrm{m}$. Figure 14 summarizes the OTU richness and Shannon

${ }^{4}$ https://tisch-env.com/product-literature/ 
TABLE 3 | Mean and standard deviation (sd) values for the percent relative abundances of selected taxa at the Phylum level.

\begin{tabular}{lcccc}
\hline Phylum & Ascent/Descent & Cruise & Ground & Hardware \\
\hline Firmicutes & $80.6(5.99)$ & $78.1(13)$ & $76.1(10.9)$ & $19(7.45)$ \\
Proteobacteria & $16.7(6.77)$ & $20.1(12.5)$ & $3.67(3.05)$ & $29.1(12.6)$ \\
Actinobacteria & $0.887(0.292)$ & $0.798(0.391)$ & $0.542(0.169)$ & $0.92(2.49)$ \\
Bacteroidetes & $1.27(1.5)$ & $0.452(0.133)$ & $0.231(0.258)$ & $0.574(0.0795)$ \\
Cyanobacteria & $0.176(0.164)$ & $0.189(0.202)$ & $0.0986(0.0955)$ & $0.0639(0.0288)$ \\
Unclassified & $0.0751(0.0931)$ & $0.0691(0.054)$ & $0.0671(0.0597)$ & $0.0358(0.0201)$ \\
Euryarchaeota & $0.0757(0.0837)$ & $0.0865(0.104)$ & $0.0322(0.0202)$ & $0.0431(0.0185)$ \\
Fusobacteria & $0.111(0.237)$ & $0.0493(0.0875)$ & $0.308(0.249)$ & $0.394(0.264)$
\end{tabular}

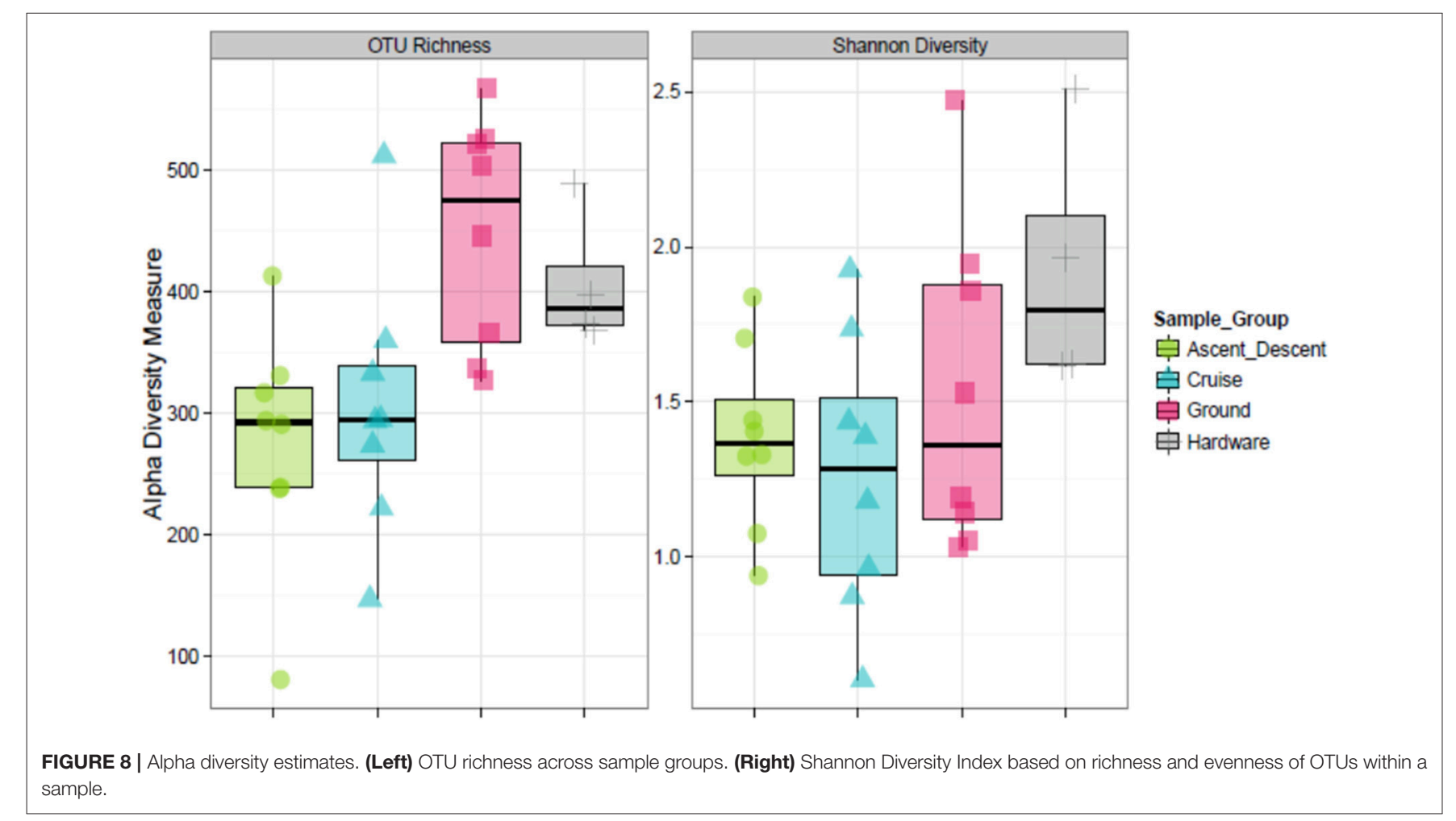

TABLE 4 | Alpha diversity differences across groups using an unpaired Kruskal-Wallis test for significance.

\begin{tabular}{lll}
\hline Comparison & Z-value & p-value \\
\hline Ascent/Descent vs. Cruise & -0.043 & 0.6704 \\
Ascent/Descent vs. Ground & -3.05 & 0.0023 \\
Cruise vs. Ground & -2.63 & 0.0086 \\
Ascent/Descent vs. Hardware & -2.22 & 0.0263 \\
Cruise vs. Hardware & -1.87 & 0.061 \\
Ground vs. Hardware & -0.027 & 0.7849 \\
\hline
\end{tabular}

Diversity between the two sampler stages. For samples collected on the first stage across all flights, the mean OTU richness was $275(\mathrm{sd}=44.9)$ and $322(\mathrm{sd}=150)$ for Ascent/Descent and Cruise groups, respectively. For samples collected on the second stage across all flights, the mean OTU richness was $276(\mathrm{sd}=140)$ and $288(\mathrm{sd}=57.1)$ for Ascent/Descent and Cruise groups, respectively. Without additional species-level identifications and microscopy data, we could not determine the size of bacterial cells, spores, and fragments contributing to OTUs measured.

\section{DISCUSSION}

Our results showed no clear differences in the richness or diversity of airborne bacteria collected at lower altitudes 0.3 to $12 \mathrm{~km}$ (Ascent/Descent samples) compared to higher altitudes $\sim 12.1 \mathrm{~km}$ (Cruise samples). Since the bacteria from these regions were more similar than different, our initial hypothesis of the tropopause serving as a naturally occurring altitude boundary for bioaerosols was not supported. Instead, our data 


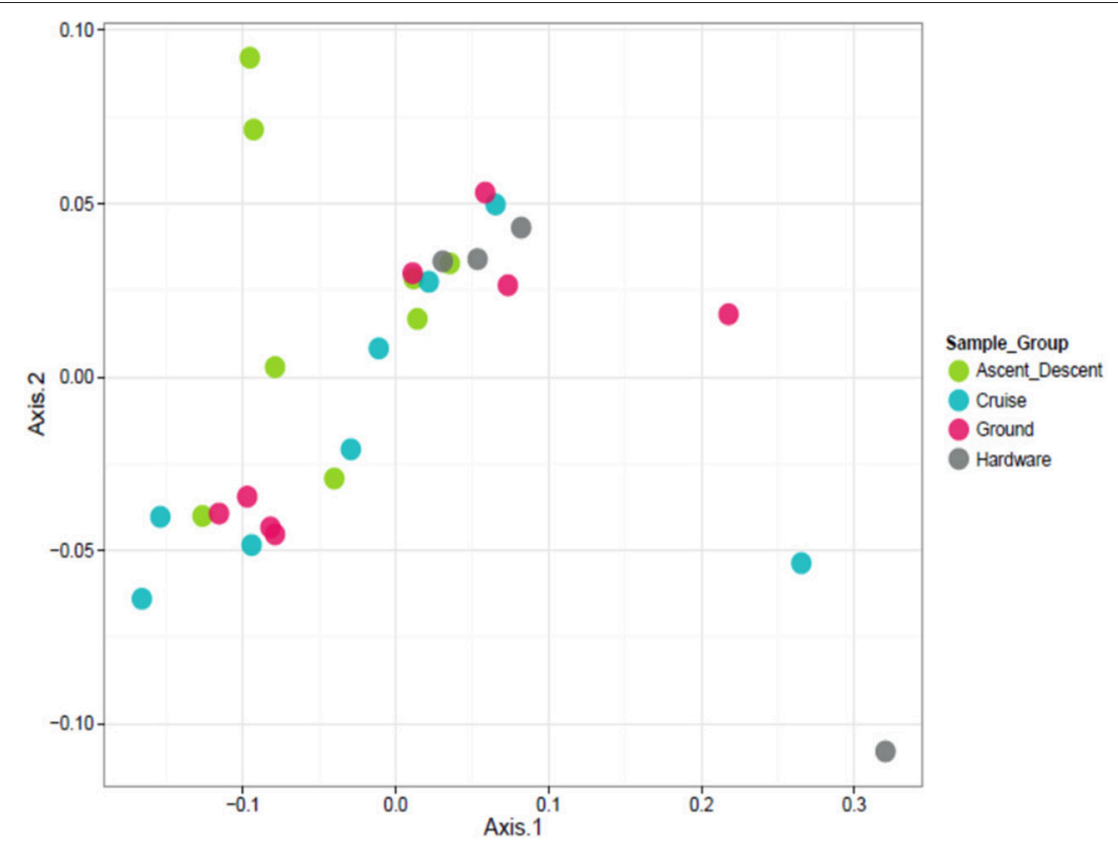

FIGURE 9 | Weighted ordination based on relative abundance showed no clustering by sample group. The first two ordination axes accounted for $77.5 \%$ of sample variation.

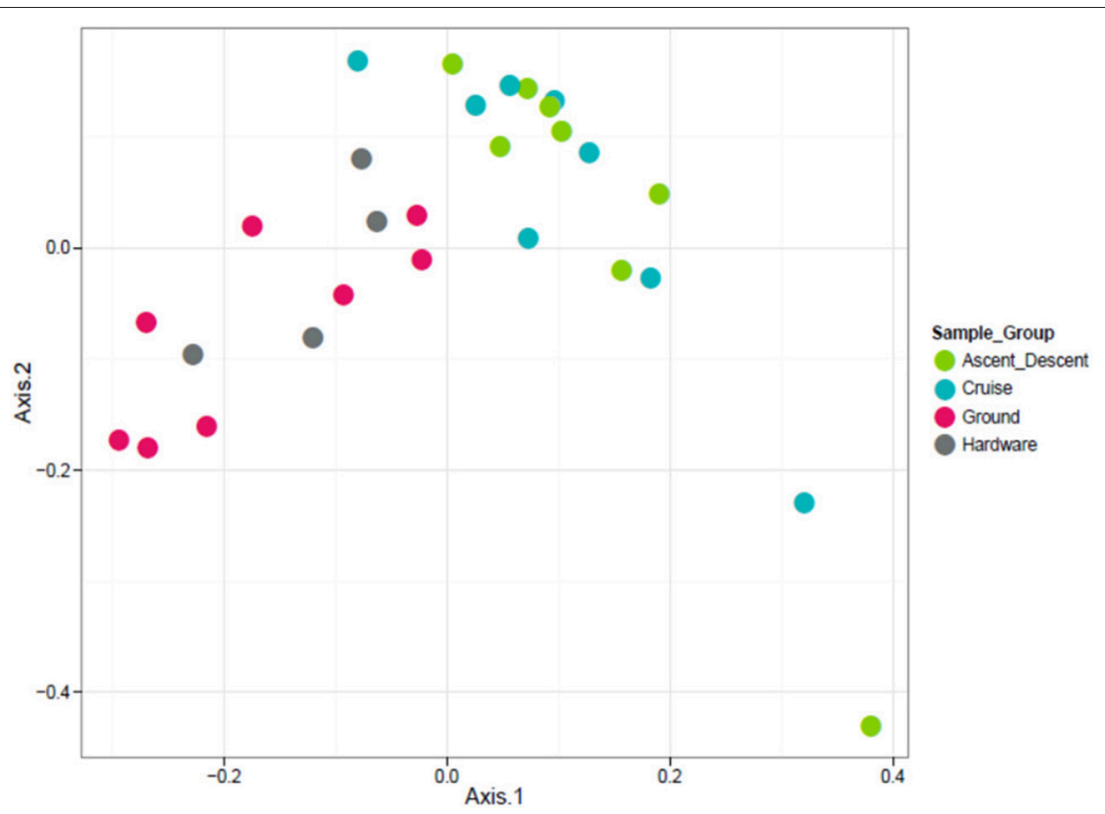

FIGURE 10 | Unweighted ordination based on presence/absence showed non-significant clustering in sample groups. Flight samples (Cruise and Ascent/Descent) separated from the Ground and Hardware samples. The first two ordination axes accounted for $23.2 \%$ of sample variation.

suggested that bacteria in the atmosphere up to $12 \mathrm{~km}$ were homogenously distributed. However, we had no way of testing whether a subset of bioaerosols from lower altitudes (i.e., Ascent/Descent samples) remained in the ABC inlet lines prior to the initiation of higher altitude collections. Such "carry-over" would be an alternative explanation for the even distribution of
OTUs measured across the troposphere and lower stratosphere. While our new ABC system showed its ability to collect bioaerosols at extreme altitudes, the influence of contaminants from hardware remained apparent-thus, inherent limitations of our dataset and areas for improvements will be discussed later. 


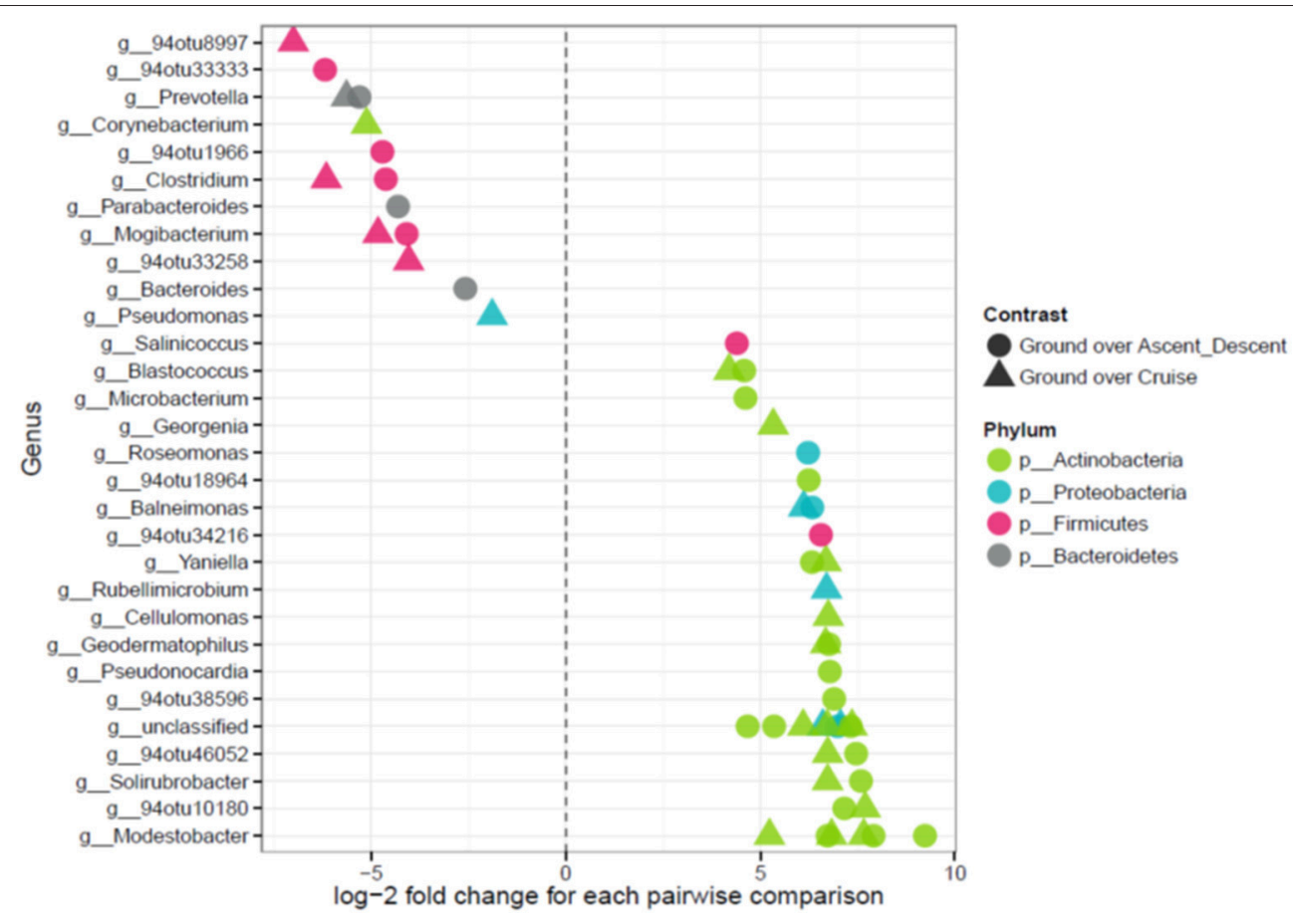

FIGURE 11 | Points on the left depict OTUs in Ascent/Descent and Cruise samples that were more abundant compared to Ground samples; points on the right depict OTUs enriched in Ground samples. Features were considered significant if FDR-corrected $p$-values were $<0.05$ and the absolute value of the log-2 fold change was $\geq 1$.

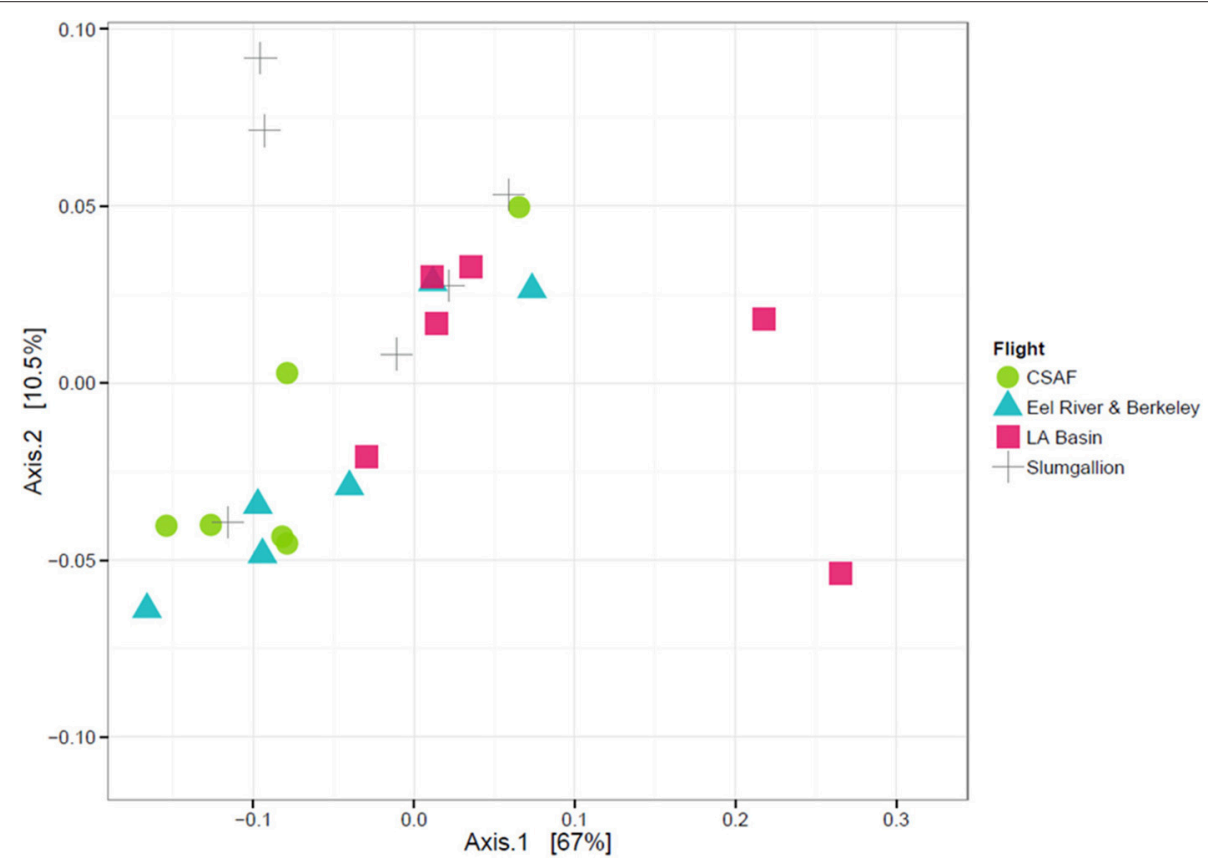

FIGURE 12 | Weighted ordination plot based on OTU abundance showing that samples did not cluster by flight. The first two ordination axes accounted for $77.5 \%$ of sample variation.

Although in relatively low abundance, the diversity of bacteria in the atmosphere seems to mirror taxa found in numerous terrestrial and aquatic ecosystems. The phyla most abundant in our study-Firmicutes, Proteobacteria, Actinobacteria, Bacteroidetes, Cyanobacteria, Euryarchaeota and Fusobacteria-are also reported widely across aerobiology 


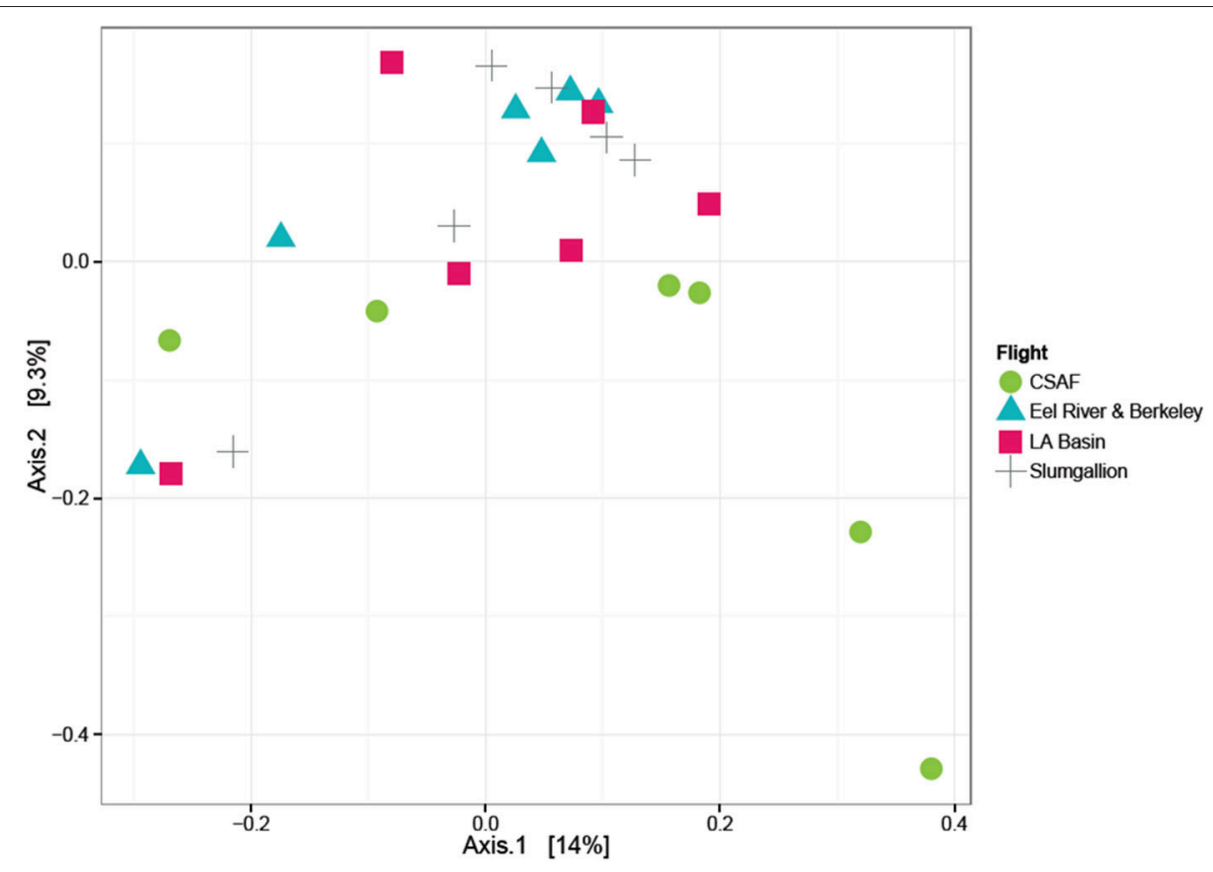

FIGURE 13 | Unweighted ordination plot based on OTU presence/absence showing that samples did not cluster by flight. The first two ordination axes accounted for $23.2 \%$ of sample variation.

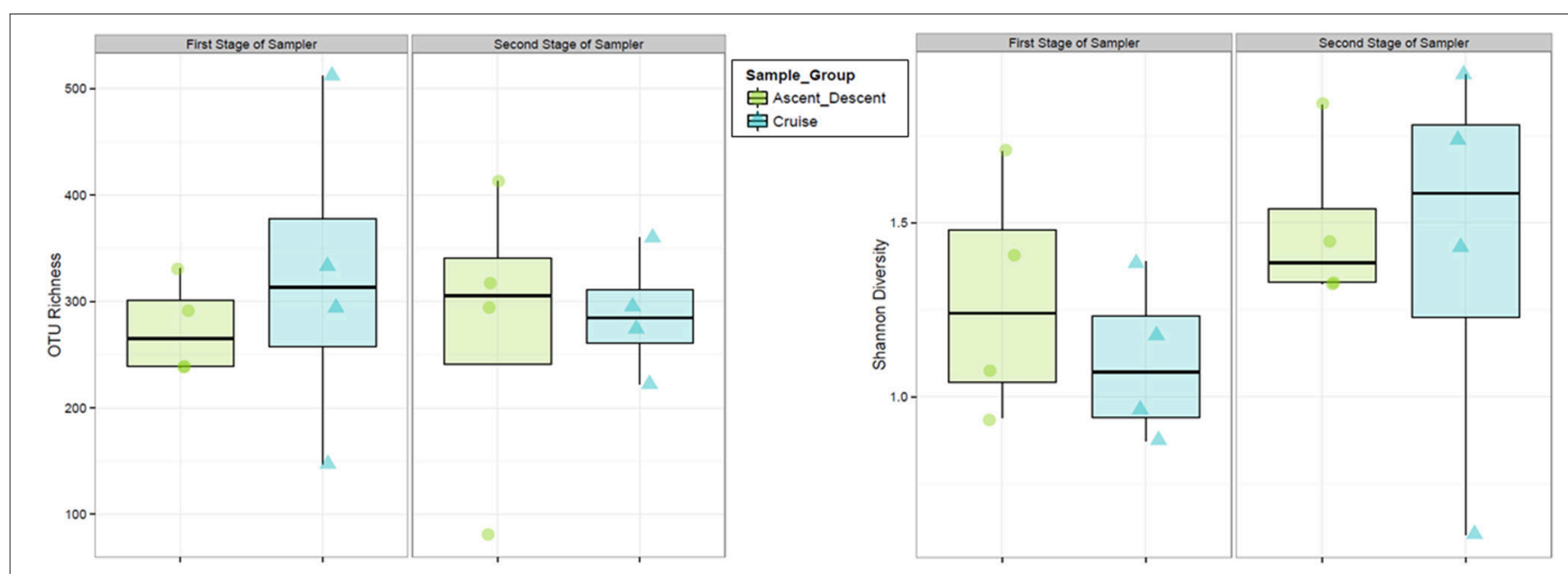

FIGURE 14 | Relative abundance and diversity of flight samples (Ascent/Descent and Cruise) collected on the two internal stages of the ABC cascade sampler.

literature, as reviewed by Amato et al. (2017a). Firmicutes (gram positive), Proteobacteria (gram negative), and to a lesser extent Actinobacteria (gram positive), represented the majority of OTUs and culture-based isolates detected in our survey. By far, the most common phyla was Firmicutes, with Bacilli and Clostridia classes in significant abundance, followed distantly by Erysipelotrichi. Firmicutes were also the predominant phyla in another upper atmosphere microbiology study conducted at an alpine observatory in central Oregon collecting transpacific bioaerosols (Smith et al., 2013). The relative abundance of Bacillus sp. and Staphylococcus sp. was expected since desiccated soils and desert dust transport embedded microorganisms into the atmosphere (Griffin et al., 2017). In addition to Staphylococcus sp., many of the atmosphere sampled OTUs from the Lachnospiraceae and Ruminococcaceae families are associated with fecal matter from agriculture fields, livestock feedlots, and human wastewater. Recent work by Bowers et al. (2013) also measured these taxa in high abundance throughout the atmospheric boundary layer. Many of the phyla from our flight samples, including Alpha- Beta- and Gammaproteobacteria, Firmicutes, and Bacteroidetes, are commonly found in air samples adjacent to coastal regions (Urbano et al., 2011). With 
most of our flights occurring over the state of California, the prevailing wind direction (traveling eastward) might have carried marine bioaerosols from the Pacific Ocean. Indeed, sea salt was present in the aerosol composition modeled at $\sim 12 \mathrm{~km}$ for all flight days. Moraxellaceae was the most abundant family from Gammaproteobacteria measured in our study samples; Oxalobacteraceae, Comamonadaceae, and Burkholderiaceae were abundant families in the Betaproteobacteria class. While their overall abundance was very low in our study $(<1 \%)$, the detection of Cyanobacteria (phototrophic), Euryarchaeota (methanogenic) and Fusobacteria (potentially pathogenic), remains noteworthy considering the wide range of phenotypes and environmental impacts of these phyla.

Clostridium, Mogibacterium, Bacteroides, Prevotella, Parabacteroides, and Corynebacterium were significantly more abundant in flight samples (Ascent/Descent and Cruise) than in ground samples. The genus Clostridium is known for endospore forming bacteria, an adaptation known to enhance the resistance to biocidal factors in the atmosphere such as ultraviolet light, desiccation, and freeze/thaw cycles. Another endospore-forming genus measured in our culture-based isolates was Bacillus. However, interestingly, it was not among the most abundant genera measured with $16 \mathrm{~S} \mathrm{~V} 4$ sequencing perhaps due to the inefficiency of lysing bacterial endospores with commercial DNA extraction kits. Besides Clostridium, genera identified as more abundant in flight samples (based on culture-independent sequencing) were non-spore forming OTUs from Mogibacterium, Bacteroides, Prevotella, Parabacteroides, and Corynebacterium. Mogibacterium and Corynebacterium are Gram-positive bacteria while Bacteroides, Prevotella, and Parabacteroides are Gram-negative bacteria; these genera are widely distributed in nature and commonly found in animal gut and oral microbiomes. Based on the prevalence of these genera, wastewater treatment facilities and agriculture producing aerosolized fecal matter could be possible sources of bacteria captured at high altitudes in this study; but establishing connections to specific emission sources was not achievable within our experimental framework.

Altogether, our study's detection of airborne bacteria in the lower stratosphere supports other reported evidence of microorganisms present at extreme altitudes (Griffin, 2004; Smith et al., 2009). In addition to Bacillus sp., other viable isolates recovered from lower stratosphere samples included Micrococcus sp., Arthrobacter sp., and Staphylococcus sp. The only other upper atmosphere microbiology studies previously reporting Micrococcus sp. were from Imshenetsky et al. (1978) and Wainwright et al. (2003) who used a sounding rocket and balloon for collections, respectively. Arthrobacter sp. and Staphylococcus sp. have not appeared in upper atmosphere aerobiology literature, to our knowledge. Independent of culturing, we were able to identify Pseudomonas stutzeri as a significantly abundant OTU in Cruise samples. This was significant for two reasons: first, $P$. stutzeri has not appeared in other stratosphere microbiology studies; and second, no specieslevel identification of bacteria acquired from the stratosphere has been reported using culture-independent methods. To date, all stratosphere species identifications have been made using limited culture-based recoveries and subsequent Sanger sequencing with 16S. Encouragingly, our ABC system demonstrated that it can collect enough biomass in the stratosphere for DNA extraction and library preparation; and for the first time, cultureindependent methods can be used to provide species-level resolution for bioaerosols above the Earth's troposphere.

We undertook extensive sampling of the C-20A aircraft itself to ensure a greater degree of confidence about in situ measurements. Based on 16S V4 sequencing data, our ground samples were clearly enriched in Blastococcus sp. BC412; Georgenia sp. JC82; Modestobacter multiseptatus; Modestobacter versicolor; Modestobacter marinus; Clostridium sordellii; Ornithinimicrobium kibberense; Yaniella sp. G5; Nocardioides sp. MSL 22; and Blastococcus jejuensis. These results identified the bacterial species abundant on the outside of the aircraft and, thus, potential influences on flight samples if free stream air models for our ABC probe's position were inaccurate. Many of the cultured isolates from ground samples were soil- and plant-associated Bacillus sp., including B. carboniphilus, $B$. crescens, B. fumarioli, B. megaterium, B. aryabhattai, B. humi, and $B$. timonesis. Other common soil bacteria Bhargavaea ginseng and Streptomyces sp. were detected on exterior portions of the aircraft, as well as Gordonia paraffinivorans, elsewhere associated with oil field environments (Xue et al., 2003). We did not determine species or strain level identities of Sanger sequenced isolates because of the short $466 \mathrm{bp}$ region measured. Wider sequencing depth may have helped determine whether bacteria from ground samples were deposited during C-20A taxi time, take-off, landing, or maintenance and fueling operations. Significant changes between pre- and post-flight ground samples assayed over the same surfaces suggest that all aircraft probably shed microorganisms into the atmosphere and inherit new biomass as well (Pfaender and Swatek, 1970). But airplane traffic is probably a minor contributor to bioaerosols injected into the global atmosphere compared to more prevalent natural and human emission sources (Wéry et al., 2017).

We expected significant differences in the relative abundance and richness of bioaerosols owed to our study's wide spatial coverage across the US. Yet, OTUs acquired from spatially diverse flights seemed strikingly similar. The lack of regional patterns contradicts another continental scale study by Barberán et al. (2015) that acquired bioaerosols from dust samples at ground locations across the US. Because our study collected samples at higher altitudes, more mixing would be expected for longer-lived aerosol species. Other explanations for differences reported across the two studies might include seasonal influences, nearby emission sources and meteorological conditions. Longerlasting studies using the C-20A would help reveal if bioaerosol concentrations shift during spring/summer months due to drier surface biomass getting aerosolized and stronger atmospheric convection patterns (Amato et al., 2017a; Wéry et al., 2017).

The incorporation of satellite data in our study offered supporting evidence for the homogenous distribution of bacterial taxa across separate flights. Both the MAIAC and MERRA2 aerosol models showed similarities in the bulk type and abundance of atmospheric aerosols. One noteworthy exception was the CSAF flight that may have captured fire-related smoke 
plumes. The concentration of solvable $\mathrm{SO}_{4}$ was also higher on the CSAF flight compared to other days, suggesting the air mass sampled was drier. Precipitation is known to be associated with bioaerosol deposition (Deguillaume et al., 2008), so the relationship between regional smoke plumes, $\mathrm{SO}_{4}$, water vapor and the presence of bioaerosols warrants future investigation.

Even with statistical testing for significance and the removal of suspected contaminants, deciphering between taxa collected in situ and taxa associated with the aircraft/hardware or sample processing was challenging. Generally, flight samples yielded more reads and unique OTUs than measured in experimental controls, but filter blanks seated into the sampler inside the aircraft still resulted in numerous reads, including some totals that were higher than flight samples. For instance, Staphylococcaceae were commonly detected (especially dnOTU1), a bacterial family associated with human skin. Considering all sample filters were loaded into the cascade sampler inside the C-20A cabin, exposure to circulating air would be a likely source of background OTUs detected in our dataset. DNA-treated filters with small fragments of irradiated DNA and 16S sequencing reagents might also have contributed to a background signal. However, the primer set used for library preparation should not have amplified highly degraded DNA fragments. Tests of pristine filters and sample reagents resulted in no amplification of DNA using $16 \mathrm{~S}$ qPCR reactions based on a standard curve derived from Acinetobacter baumannii. Thus, the source of baseline reads from negative controls were probably due to the influence of cabin air inside the C-20A. To address this baseline signal, we discarded OTUs from negative controls that had a higher mean in negative controls than in samples and yielded a mean relative abundance in negative controls $>1 \%$.

Our pitot-style probe method of bioaerosol collection surely affected the type, size and number of bacteria captured in flight. For instance, biomass $>4 \mu \mathrm{m}$ likely could not enter the probe. Some bioaerosols could have been lost inside the probe and inlet lines, too, though by mounting the hardware to the C-20A window plate we reduced the distance air traveled through the system. Overall, there remains a general need for standardized sampling methods in aerobiology because disparate collection techniques introduce variation and make horizontal comparisons difficult (Griffin et al., 2010; Amato et al., 2017b). Even an imperfect sampler used repeatedly by investigators sharing downstream methods could offer important insight into currently unknown aerobiology patterns. Historically, aerobiology studies using aircraft have relied upon culturebased recovery methods (with a bias toward heterotrophic plate counts) that underestimate the true quantity and diversity of bacteria in the upper atmosphere-this approach cannot identify slow-growing, unculturable, or inactivated bacteria, including fragmented cell components. Molecular methods address the limitation but do not readily distinguish between living and dead bacteria. Thus, a substantial portion of microbes detected by DNA sequencing might exist only as debris. In the spaceflight research community, a propidium monoazide (PMA) sequencing pre-treatment has been used as a viability marker to differentiate microbial sequences from dead cells vs. intact cells (Checinska et al., 2015). Future studies utilizing molecular methods might also consider standardizing primer sets and pursuing shotgun metagenomics assays in order to reduce bias associated with 16S reference databases which still contain many unclassified taxa. Our 16S V4 primers were based on the Earth Microbiome Project (Apprill et al., 2015; Parada et al., 2015; Walters et al., 2016) aimed at maximally inclusive coverage, but marine bacteria would still be under-detected due to repository biases.

By introducing the $\mathrm{ABC}$, our hope is that other investigators can utilize the system for future aircraft studies or reproduce its basic components. All parts were easily manufactured or took advantage of relatively low cost commercially available products that can be obtained and installed on aircraft by follow-on investigator teams. For instance, the gelatinous filter we used was DNA-treated with gamma irradiation; often, field teams use sterile filters but such products still have a substantial DNA signal. Studies using other types of filters typically include aggressive methods to dislodge biomass (Smith et al., 2013), like vortexing or bead beating, introducing bias or damaging biomolecules (DeSantis et al., 2005). Another advantage of the gelatinous filter was that it could be dissolved in buffer, making the recovery of embedded bacteria $100 \%$ efficient for both culture-based and molecular methods. Because our flights were in arid regions and most of the sampling time was in the stratosphere with very low relative humidity, premature filter dissolving was not an issue for our system. In future years, we will pursue several modifications to the $\mathrm{ABC}$ system for improving bioaerosol capture and reducing system contaminants: (1) manufacturing a probe with a larger diameter to increase air flow rates above $8.51 \cdot \mathrm{min}^{-1}$; (2) installing a valve at the probe opening to stop air from entering the inlet lines during take-off and landing; (3) building a glovebox on the C-20A workbench to accommodate the cascade sampler and prevent the cabin air from settling onto system surfaces; (4) creating a new filter membrane support grid from aluminum (not plastic) for easier pre-flight sterilization; and (5) recording system air volumes processed with a digitallyrecorded flow meter. If combined with post-flight quantitative assays (e.g., cell counts though fluorescent microscopy or DNA abundance estimates with qPCR reactions), more precise air flow measurements would help establish global models of bioaerosol concentration, vertical distribution and atmospheric residence time.

It will always be difficult to determine bioaerosol origins given the tapestry of known emission sources and potential for long range atmospheric dispersal. A useful regional scale study might have sampling stations proximally-positioned to major aerosolization sources (e.g., wastewater treatment facilities, livestock feedlots). Downwind areas could then be sampled extensively with aircraft sweeps at multiple heights to make better correlations across time and space. Huffman and Santarpia (2017) discuss the importance of including "online" instruments on aircraft used for future aerobiology missions. Particle counters or LIDARs would be valuable for making real-time decisions in the air about where to sample and also for establishing stronger correlations between spectroscopic/fluorescent measurements and microorganisms identified later in the laboratory. Ultimately, studies should strive toward more routine and widespread flux measurements, analogous to other globally-tracked gaseous 
aerosol species (e.g., carbon dioxide, water vapor, ozone, nitrogen compounds) (Wéry et al., 2017).

Worldwide, bioaerosols are thought to represent $5-50 \%$ of atmospheric particles $>0.2 \mu \mathrm{m}$ in diameter (Jaenicke, 2005; Després et al., 2012) and yet our current understanding of emission sources, transport history, and vertical distribution is quite rudimentary. Considering airborne biomass can travel thousands of kilometers over days if not weeks (Smith et al., 2013), atmospheric disease corridors likely exist (Prospero, 1999; Prospero et al., 2005), biodiversity impacts occur with microbes landing in new environments (Morris and Sands, 2017), and cloud chemistry and precipitation rates can be altered by cells (Delort et al., 2017; Hill et al., 2017), more coordinated, international research campaigns using aircraft in the troposphere and stratosphere should fly in future years. While addressing basic research questions about the dynamics of airborne microbes in the Earth's upper atmosphere, we can also gain knowledge about how to reliably collect and characterize trace levels of biomass present in extreme environments-such techniques will be relevant to astrobiology and the search for life on other worlds.

\section{AUTHOR CONTRIBUTIONS}

DS led the study, designed the experiment and wrote the first draft of the manuscript. JDR and SJ performed the statistical analyses and compiled results from sequencing data. DG, PN, and SS did culture-based isolations, nucleic acid extractions and Sanger sequencing. KS extracted DNA for 16S V4 samples and conducted sequencing runs. HY and QT generated aerosol modeling data and analysis. TL, PM, AO, JL, SC, and JM provided

\section{REFERENCES}

Acosta-Martinez, V., Van Pelt, S., Moore-Kucera, J., Baddock, M. C., and Zobeck, T. M. (2015). Microbiology of wind-eroded sediments: current knowledge and future research directions. Aeolian Res. 18, 99-113. doi: 10.1016/j.aeolia.2015.06.001

Alhasson, F., Das, S., Seth, R., Dattaroy, D., Chandrashekaran, V., Ryan, C. N., et al. (2017). Altered gut microbiome in a mouse model of gulf war illness causes neuroinflammation and intestinal injury via leaky gut and TLR4 activation. PLOS ONE 12:e0172914. doi: 10.1371/journal.pone.01 72914

Amato, P., Brisebois, E., Draghi, M., Duchaine, C., Fröhlich-Nowoisky, J., and Huffman, J., et al. (2017a)."Main biological aerosols, specificities, abundance, and diversity," in Microbiology of Aerosols, eds A. M. Delort and P. Amato (Hoboken, NJ: John Wiley \& Sons, Inc.), 1-21.

Amato, P., Brisebois, E., Draghi, M., Duchaine, C., Fröhlich-Nowoisky, J., Huffman, J., et al. (2017b). "Sampling techniques," in Microbiology of Aerosols, eds A. M. Delort and P. Amato (Hoboken, NJ: John Wiley \& Sons, Inc.), 23-48.

Amato, P., Joly, M., Besaury, L., Oudart, A., Taib, N., Moné, A. I., et al. (2017c). Active microorganisms thrive among extremely diverse communities in cloud water. PLoS ONE 12:e0182869. doi: 10.1371/journal.pone.0182869

Amato, P., Joly, M., Schaupp, C., Attard, E., Möhler, O., Morris, C., et al. (2015). Survival and ice nucleation activity of bacteria as aerosols in a cloud simulation chamber. Atmos. Chem. Phys. Discuss. 15, 4055-4082. doi: 10.5194/acpd-15-4055-2015

Anderson, M. J. (2001). A new method for non-parametric multivariate analysis of variance. Austral. Ecol. 26, 32-46. doi: 10.1111/j.1442-9993.2001.01070.pp.x engineering for the $\mathrm{ABC}$ design, instrument manufacturing and C-20A support. KI, LC, JT, and CJ reviewed the analysis, helped with data interpretation, and provided technical support. All authors contributed to reviewing, editing, and finalizing the manuscript.

\section{ACKNOWLEDGMENTS}

Our study was funded by the NASA Office of the Chief Scientist (FY17 Science Innovation Fund award), a FY17/18 Biodiversity grant from the NASA Earth Science Division, internal awards from NASA Ames Research Center and Lawrence Livermore National Laboratory (LLNL) in FY18, and the U.S. Geological Survey's Environmental Health Toxic Substances Hydrology and Contaminate Biology Programs. C$20 \mathrm{~A}$ ride along flights were generously provided by the Airborne Science Program at NASA Armstrong Flight Research Center and members of the UAVSAR science team from the Jet Propulsion Laboratory. We thank J. Green and H. Wilson at the University of Oregon, W. K. Kan at NASA Ames, and J. Payne from InnovaPrep LLC for loaning equipment and instruments to our team. Logistical support was invaluably provided by S. Bhattacharya (NASA Ames) and S. Parker (Wyle Labs). S. Palacios from the Bay Area Environmental Research Institute, L. Rothschild at NASA Ames, A. Schuerger from the University of Florida, and M. Dillon at LLNL all provided feedback during the project planning phase and we are grateful for their time and insight. Finally, we acknowledge several open source products and data used in our study, including HYSPLIT from NOAA, BLAST from NIH, and MODIS/MAIAC from NASA.
Apprill, A., McNally, S., and Parsons, R., Weber, L. (2015). Minor revision to V4 region SSU rRNA 806R gene primer greatly increases detection of SAR11 bacterioplankton. Aquat. Microb. Ecol. 75, 129-137. doi: 10.3354/ ame 01753

Barberán, A., Ladau, J., Leff, J. W., Pollard, K. S., Menninger, H. L., Dunn, R. R., et al. (2015). Continental-scale distributions of dust-associated bacteria and fungi. Proc. Natl. Acad. Sci. U.S.A. 112, 5756-5761. doi: $10.1073 /$ pnas. 1420815112

Benardini, J. N. III., La Duc, M. T., Beaudet, R. A., and Koukol, R. (2014). Implementing planetary protection measures on the Mars Science Laboratory. Astrobiology 14, 27-32. doi: 10.1089/ast. 2013.0989

Benjamini, Y., and Hochberg, Y. (1995). Controlling the false discovery rate: a practical and powerful approach to multiple testing. J. R. Stat. Soc. Seri. B. Stat. Methodol. 57, 289-300.

Borodulin, A. I., Safatov, A. S., Shabanov, A. N., Yarygin, A. A., Khutorova, O. G., Belan, B. D., et al. (2005). Physical characteristics of concentration fields of tropospheric bioaerosols in the South of Western Siberia. J. Aerosol Sci. 36, 785-800. doi: 10.1016/j.jaerosci.2004. 12.009

Bovallius, Å., Roffey, R., and Henningson, E. (2006). Long-range transmission of bacteria. Ann. N.Y. Acad. Sci. 353, 186-200. doi: 10.1111/j.1749-6632.1980.tb18922.x

Bowers, R. M., Clements, N., Emerson, J. B., Wiedinmyer, C., Hannigan, M. P., and Fierer, N. (2013). Seasonal variability in bacterial and fungal diversity of the near-surface atmosphere. Environ. Sci. Technol. 47, 12097-12106. doi: $10.1021 /$ es402970s 
Bowers, R. M., Lauber, C. L., Wiedinmyer, C., Hamady, M., Hallar, A. G., Fall, R., et al. (2009). Characterization of airborne microbial communities at a high-elevation site and their potential to act as atmospheric ice nuclei. Appl. Environ. Microbiol. 75, 5121-5130. doi: 10.1128/AEM.0 0447-09

Bowers, R. M., Sullivan, A. P., Costello, E. K., Collett, J. L. Jr., Knight, R., and Fierer, N. (2011). Sources of bacteria in outdoor air across cities in the midwestern United States. Appl. Environ. Microbiol. 77, 6350-6356. doi: 10.1128/AEM.05498-11

Brown, J. K., and Hovmoller, M. S. (2002). Aerial dispersal of pathogens on the global and continental scales and its impact on plant disease. Science 297, 537-541. doi: 10.1126/science.1072678

Bryan, N., Stewart, M., Granger, D., Guzik, T., and Christner, B. (2014). A method for sampling microbial aerosols using high altitude balloons. J. Microbiol. Methods 107, 161-168. doi: 10.1016/j.mimet.2014. 10.007

Burrows, S., Butler, T., Jöckel, P., Tost, H., Kerkweg, A., Pöschl, U., et al. (2009a). Bacteria in the global atmosphere-Part 2: modeling of emissions and transport between different ecosystems. Atmos. Chem. Phys. 9, 9281-9297. doi: 10.5194/acp-9-9281-2009

Burrows, S., Elbert, W., Lawrence, M., and Pöschl, U. (2009b). Bacteria in the global atmosphere-Part 1: review and synthesis of literature data for different ecosystems. Atmos. Chem. Phys. 9, 9263-9280. doi: 10.5194/acp-9-92 63-2009

Checinska, A., Probst, A. J., Vaishampayan, P., White, J. R., Kumar, D., Stepanov, V. G., et al. (2015). Microbiomes of the dust particles collected from the international space station and spacecraft assembly facilities. Microbiome 3:50. doi: 10.1186/s40168-015-0116-3

Chudobova, D., Cihalova, K., Jelinkova, P., Zitka, J., Nejdl, L., Guran, R., et al. (2015). Effects of stratospheric conditions on the viability, metabolism and proteome of prokaryotic cells. Atmosphere 6, 1290-1306. doi: 10.3390/atmos6091290

Deguillaume, L., Leriche, M., Amato, P., Ariya, P., Delort, A.-M., Pöschl, U., et al. (2008). Microbiology and atmospheric processes: chemical interactions of primary biological aerosols. Biogeosci. Discuss. 5, 841-870. doi: 10.5194/bgd-5-841-2008

DeLeon-Rodriguez, N., Lathem, T. L., Rodriguez, R. L., Barazesh, J. M., Anderson, B. E., Beyersdorf, A. J., et al. (2013). Microbiome of the upper troposphere: species composition and prevalence, effects of tropical storms, and atmospheric implications. Proc. Natl. Acad. Sci. U.S.A. 110, 2575-2580. doi: $10.1073 /$ pnas. 1212089110

Delort, A. M., Deguillaume, L., Renard, P., Vinatier, V., Canet, I., Vaïtilingom, M., et al. (2017). "Impacts on cloud chemistry" in Microbiology of Aerosols, eds A. M. Delort and P. Amato (Hoboken, NJ: John Wiley \& Sons, Inc.), 221-248.

DeSantis, T. Z., Stone, C. E., Murray, S. R., Moberg, J. P., and Anderson, G. L. (2005). Rapid quantification and taxonomic classification of environmental DNA from both prokaryotic and eukaryotic origins using a microrray. FEMS Microbiol. Lett. 245, 271-278. doi: 10.1016/j.femsle.2005. 03.016

Després, V., Huffman, J. A., Burrows, S. M., Hoose, C., Safatov, A., Buryak, G., et al. (2012). Primary biological aerosol particles in the atmosphere: a review. Tellus Ser. B: Chem. Phys. Meteorol. 64:15598. doi: 10.3402/tellusb.v64i0. 15598

Dibb, J. E., Talbot, R., Scheuer, E., Blake, D., Blake, N., Gregory, G., et al. (1999). Aerosol chemical composition and distribution during the pacific exploratory mission (PEM) tropics. J. Geophys. Res. Atmos. 104, 5785-5800. doi: 10.1029/1998JD100001

Edgar, R. C. (2013). UPARSE: highly accurate OTU sequences from microbial amplicon reads. Nat. Methods 10, 996-998. doi: 10.1038/nmeth.2604

Favet, J., Lapanje, A., Giongo, A., Kennedy, S., Aung, Y. Y., Cattaneo, A., et al. (2012). Microbial hitchhikers on intercontinental dust: catching a lift in Chad. ISME J. 7, 850-867. doi: 10.1038/ismej. 2012.152

Fröhlich-Nowoisky, J., Kampf, C. J., Weber, B., Huffman, J. A., Pöhlker, C., Andreae, M. O., et al. (2016). Bioaerosols in the earth system: climate, health, and ecosystem interactions. Atmos. Res. 182, 346-376. doi: 10.1016/j.atmosres.2016.07.018
Gat, D., Mazar, Y., Cytryn, E., and Rudich, Y. (2017). Origin-dependent variations in the atmospheric microbiome community in eastern Mediterranean dust storms. Environ. Sci. Technol. 51, 6709-6718. doi: 10.1021/acs.est.7b 00362

Gelaro, R., McCarty, W., Suarez, M. J., Todling, R., Molod, A., Takacs, L., et al. (2017). The modern-era retrospective analysis for research and applications, version 2 (MERRA-2). J. Clim. 30, 5419-5454. doi: 10.1175/JCLI-D-160758.1

Griffin, D. W. (2004). Terrestrial microorganisms at an altitude of $20,000 \mathrm{~m}$ in earth's atmosphere. Aerobiologia 20, 135-140. doi: 10.1023/B:AERO.0000032948.84077.12

Griffin, D. W., Gonzalez, C., Teigell, N., Petrosky, T., Northup, D. E., and Lyles, M. (2010). Observations on the use of membrane filtration and liquid impingement to collect airborne microorganisms in various atmospheric environments. Aerobiologia 27, 25-35. doi: 10.1007/s10453-0109173-z

Griffin, D., Gonzalez-Martin, C., Hoose, C., and Smith, D. (2017). "Globalscale atmospheric dispersion of microorganisms," in Microbiology of Aerosols, eds A. M. Delort and P. Amato (Hoboken, NJ: John Wiley \& Sons, Inc.), 155-194.

Hill, K. A., Shepson, P. B., Galbavy, E. S., Anastasio, C., Kourtev, P. S., Konopka, A., et al. (2007). Processing of atmospheric nitrogen by clouds above a forest environment. J. Geophys. Res. Atmos. 112, 1-16. doi: 10.1029/2006JD008002

Hill, T. C., DeMott, P., Conen, F., and Möhler, O. (2017). "Impacts of bioaerosols on atmospheric ice nucleation processes," in Microbiology of Aerosols, eds A. M. Delort and P. Amato (Hoboken, NJ: John Wiley \& Sons, Inc.), 195-219.

Huffman, J., and Santarpia, J. (2017). "Online techniques for quantification and characterization of biological aerosols," in Microbiology of Aerosols, eds A. M. Delort and P. Amato (Hoboken, NJ: John Wiley \& Sons, Inc.), 83-114.

Imshenetsky, A., Lysenko, S., and Kazakov, G. (1978). Upper boundary of the biosphere. Appl. Environ. Microbiol. 35, 1-5.

Jaenicke, R. (2005). Abundance of cellular material and proteins in the atmosphere. Science 308, 73-73. doi: 10.1126/science.1106335

Khodadad, C. L., Wong, G. M., James, L. M., Thakrar, P. J., Lane, M. A. Catechis, J. A., et al. (2017). Stratosphere conditions inactivate bacterial endospores from a Mars spacecraft assembly facility. Astrobiology 17, 337-350. doi: $10.1089 /$ ast.2016.1549

King, W. (1984). Air flow and particle trajectories around aircraft fuselages. I: theory. J. Atmos. Oceanic. Technol. 1, 5-13. doi: 10.1175/1520-0426(1984)001\&lt;0005:AFAPTA\&gt;2.0.CO;2

Klein, A. M., Bohannan, B. J., Jaffe, D. A., Levin, D. A., and Green, J. L. (2016) Molecular evidence for metabolically active bacteria in the atmosphere. Front. Microbiol. 7:772. doi: 10.3389/fmicb.2016.00772

Koo, V. C., Chan, Y. K., Vetharatnam, G., Chua, M. Y., Lim, C. H., Lim, C.-S., et al. (2012). A new unmanned aerial vehicle synthetic aperture radar for environmental monitoring. Prog. Electromagn. Res. 122, 245-268. doi: 10.2528/PIER11092604

Love, M. I., Huber, W., and Anders, S. (2014). Moderated estimation of fold change and dispersion for RNA-seq data with DESeq2. Genome Biol. 15:550. doi: 10.1186/s13059-014-0550-8

Lyapustin, A., Wang, Y., Laszlo, I., Kahn, R., Korkin, S., Remer, L., et al. (2011). Multiangle implementation of atmospheric correction (MAIAC): 2. Aerosol algorithm. J. Geophys. Res. Atmos. 116, 1-15. doi: 10.1029/2010JD014986

Mahaffee, W. F., and Stoll, R. (2016). The ebb and flow of airborne pathogens: monitoring and use in disease management decisions. Phytopathology 106, 420-431. doi: 10.1094/PHYTO-02-16-0060-RVW

Maki, T., Hara, K., Iwata, A., Lee, K. C., Kawai, K., Kai, K., et al. (2017). Variations in airborne bacterial communities at high altitudes over the Noto Peninsula (Japan) in response to Asian dust events. Atmos. Chem. Phys. 17, 11877-11897. doi: 10.5194/acp-17-11877-2017

Maki, T., Kakikawa, M., Kobayashi, F., Yamada, M., Matsuki, A., Hasegawa, H., et al. (2013). Assessment of composition and origin of airborne bacteria in the free troposphere over Japan. Atmos. Environ. 74, 73-82. doi: 10.1016/j.atmosenv.2013.03.029

McDonald, D., Price, M. N., Goodrich, J., Nawrocki, E. P., DeSantis, T. Z., Probst, A., et al. (2012). An improved Greengenes taxonomy with explicit ranks for ecological and evolutionary analyses of bacteria and archaea. ISME J. 6, 610-618. doi: 10.1038/ismej.2011.139 
McMurdie, P. J., and Holmes, S. (2013). Phyloseq: an R package for reproducible interactive analysis and graphics of microbiome census data. PLoS ONE 8:e61217. doi: 10.1371/journal.pone.0061217

McMurdie, P. J., and Holmes, S. (2014). Waste not, want not: why rarefying microbiome data is inadmissible. PLoS Comput. Biol. 10:e1003531. doi: 10.1371/journal.pcbi.1003531

Meier, F. C., and Lindbergh, C. A. (1935). Collecting micro-organisms from the arctic atmosphere: with field notes and material. Sci. Mon. 40, 5-20.

Mohan, M., Chow, C. E. T., Ryan, C. N., Chan, L. S., Dufour, J., Aye, P. P., et al. (2016). Dietary gluten-induced gut dysbiosis is accompanied by selective upregulation of microRNAs with intestinal tight junction and bacteriabinding motifs in Rhesus Macaque model of celiac disease. Nutrients 8:684. doi: $10.3390 /$ nu8110684

Morris, C., and Sands, D. (2017). "Impacts of microbial aerosols on natural and agro-ecosystems: immigration, invasions, and their consequences," in Microbiology of Aerosols, eds A. M. Delort and P. Amato (Hoboken, NJ: John Wiley \& Sons, Inc.), 269-279.

Nadkarni, M. A., Martin, F. E., Jacques, N. A., and Hunter, N. (2002). Determination of bacterial load by real-time PCR using a broadrange (universal) probe and primers set. Microbiology 148, 257-266. doi: 10.1099/00221287-148-1-257

Oksanen, J., Blanchet, F. G., Kindt, R., Legendre, P., O’hara, R., Simpson, G. L., et al. (2010). Vegan: Community Ecology Package. R package version 1.17-2. R Development Core Team. R: A language and environment for statistical computing. Vienna: R Foundation for Statistical Computing.

Parada, A. E., Needham, D. M., and Fuhrman, J. A. (2015). Every base matters: assessing small subunit rRNA primers for marine microbiomes with mock communities, time series and global field samples. Environ. Microb. 18, 1403-1414. doi: 10.1111/1462-2920.13023

Pfaender, F. K., and Swatek, F. E. (1970). Interenvironmental transfer of microorganisms on the exterior surfaces of jet aircraft. Appl. Microbiol. 20, 227-232.

Polunin, N., and Kelly, C. (1952). Arctic aerobiology: fungi and bacteria, etc., caught in the air during flights over the geographical North Pole. Nature 170, 314-316.

Prospero, J. M. (1999). Long-range transport of mineral dust in the global atmosphere: impact of African dust on the environment of the southeastern United States. Proc. Natl. Acad. Sci. U.S.A. 96, 3396-3403. doi: 10.1073/pnas.96.7.3396

Prospero, J. M., Blades, E., Mathison, G., and Naidu, R. (2005). Interhemispheric transport of viable fungi and bacteria from Africa to the Caribbean with soil dust. Aerobiologia 21, 1-19. doi: 10.1007/s10453-004-5872-7

Reche, I., D'Orta, G., Mladenov, N., Winget, D. M., and Suttle, C. A. (2018). Deposition rates of viruses and bacteria above the atmospheric boundary layer. ISME J. 12, 1154-1162. doi: 10.1038/s41396-017-0042-4

Reveles, K. R., Ryan, C. N., Chan, L., Cosimi, R. A., and Haynes, W. L. (2017). Proton pump inhibitor use associated with changes in gut microbiota composition. Gut 67, 1369-1370. doi: 10.1136/gutjnl-2017-315306

Scheuer, E., Talbot, R. W., Dibb, J. E., Seid, G. K., DeBell, L., and Lefer, B. (2003). Seasonal distributions of fine aerosol sulfate in the North American Arctic basin during TOPSE. J. Geophys. Res. Atmos. 108, 1-11. doi: 10.1029/2001JD001364

Schmale, D. G. III., and Ross, S. D. (2015). Highways in the sky: scales of atmospheric transport of plant pathogens. Ann. Rev. Phytopathol. 53, 591-611. doi: 10.1146/annurev-phyto-080614-115942

Smith, D. J. (2013). Microbes in the upper atmosphere and unique opportunities for astrobiology research. Astrobiology 13, 981-990. doi: 10.1089/ast.2013.1074

Smith, D. J., and Griffin, D. W. (2013). Inadequate methods and questionable conclusions in atmospheric life study. Proc. Natl. Acad. Sci. U.S.A. 110, E2084. doi: $10.1073 /$ pnas. 1302612110

Smith, D. J., Griffin, D. W., McPeters, R. D., Ward, P. D., and Schuerger, A. C. (2011). Microbial survival in the stratosphere and implications for global dispersal. Aerobiologia 27, 319-332. doi: 10.1007/s10453-0119203-5

Smith, D. J., Griffin, D. W., and Schuerger, A. C. (2009). Stratospheric microbiology at $20 \mathrm{~km}$ over the Pacific Ocean. Aerobiologia 26, 35-46. doi: 10.1007/s10453-009-9141-7

Smith, D. J., Jaffe, D. A., Birmele, M. N., Griffin, D. W., Schuerger, A. C., Hee, J., et al. (2012). Free tropospheric transport of microorganisms from
Asia to North America. Microb. Ecol. 64, 973-985. doi: 10.1007/s00248-0120088-9

Smith, D. J., Timonen, H. J., Jaffe, D. A., Griffin, D. W., Birmele, M. N., Perry, K. D., et al. (2013). Intercontinental dispersal of bacteria and archaea by transpacific winds. Appl. Environ. Microbiol. 79, 1134-1139. doi: 10.1128/AEM.03 029-12

Stein, A., Draxler, R. R., Rolph, G. D., Stunder, B. J., Cohen, M., and Ngan, F. (2015). NOAA's HYSPLIT atmospheric transport and dispersion modeling system. Bull. Am. Meteorol. Soc. 96, 2059-2077. doi: 10.1175/BAMS-D-14-0 0110.1

Summons, R., Sessions, A. L., Allwood, A., Barton, H., Beaty, D., Blakkolb, B., et al. (2014). Planning considerations related to the organic contamination of Martian samples and implications for the Mars 2020 rover. Astrobiology 14, 969-1027. doi: 10.1089/ast.2014.1244

Talbot, R., Dibb, J. E., and Loomis, M. (1998). Influence of vertical transport on free tropospheric aerosols over the central USA in springtime. Geophys. Res. Lett. 25, 1367-1370. doi: 10.1029/98GL 00184

Tang, K., Huang, Z., Huang, J., Maki, T., Zhang, S., Ma, X., et al. (2016). Characterization of atmospheric bioaerosols along the transport pathway of Asian dust during the Dust-Bioaerosol 2016 Campaign. Atmos. Chem. Phys. Discuss. 18, 7131-7148. doi: 10.5194/acp-18-71 31-2018

Timmons, D. E., Fulton, J. D., and Mitchell, R. B. (1966). Microorganisms of the upper atmosphere I. Instrumentation for isokinetic air sampling at altitude. Appl. Microbiol. 14, 229-231.

Toepfer, I., Favet, J., Schulte, A., Schmölling, M., Butte, W., Triplett, E. W., et al. (2011). Pathogens as potential hitchhikers on intercontinental dust. Aerobiologia 28, 221-231. doi: 10.1007/s10453-0119230-2

Trägårdh, C. (1977). Sampling of aerobiological material from a small aircraft. Grana 16, 139-143. doi: 10.1080/00173134.1977.118 64649

Urbano, R., Palenik, B., Gaston, C., and Prather, K. (2011). Detection and phylogenetic analysis of coastal bioaerosols using culture dependent and independent techniques. Biogeosciences 8, 301-309. doi: 10.5194/bg-8301-2011

Vaïtilingom, M., Amato, P., Sancelme, M., Laj, P., Leriche, M., and Delort, A. M. (2010). Contribution of microbial activity to carbon chemistry in clouds. Appl. Environ. Microbiol. 76, 23-29. doi: 10.1128/AEM.0 1127-09

Vaïtilingom, M., Deguillaume, L., Vinatier, V., Sancelme, M., Amato, P., Chaumerliac, N., et al. (2013). Potential impact of microbial activity on the oxidant capacity and organic carbon budget in clouds. Proc. Natl. Acad. Sci. U.S.A. 110, 559-564. doi: 10.1073/pnas.1205 743110

Vaishampayan, P., Probst, A. J., La Duc, M. T., Bargoma, E., Benardini, J. N., Andersen, G. L., et al. (2013). New perspectives on viable microbial communities in low-biomass cleanroom environments. ISME J. 7, 312-324. doi: 10.1038 /ismej.2012.114

Van Leuken, J., Swart, A., Havelaar, A., Van Pul, A., Van der Hoek, W., and Heederik, D. (2016). Atmospheric dispersion modelling of bioaerosols that are pathogenic to humans and livestock-a review to inform risk assessment studies. Microb. Risk Anal. 1, 19-39. doi: 10.1016/j.mran.2015. 07.002

Wainwright, M., Wickramasinghe, N., Narlikar, J., and Rajaratnam, P. (2003). Microorganisms cultured from stratospheric air samples obtained at $41 \mathrm{~km}$. FEMS Microbiol. Lett. 218, 161-165. doi: 10.1111/j.1574-6968.2003.tb1 1513.x

Walters, W., Hyde, E. R., Berg-Lyons, D., Ackermann, G., Humphrey, G., Parada, A., et al. (2016). Improved bacterial 16S rRNA gene (V4 and V4-5) and fungal internal transcribed spacer marker gene primers for microbial community surveys. mSystems 1:e00009-15. doi: 10.1128/mSystems.00009-15

Waters, S. M., Zeigler, D. R., and Nicholson, W. L. (2015). Experimental evolution of Bacillus subtilis to enhanced growth at low atmospheric pressure: genomic changes revealed by whole genome sequencing. Appl. Environ. Microbiol. 81, 7525-7532. doi: 10.1128/AEM.0 1690-15 
Weil, T., De Filippo, C., Albanese, D., Donati, C., Pindo, M., Pavarini, L., et al. (2017). Legal immigrants: invasion of alien microbial communities during winter occurring desert dust storms. Microbiome 5:32. doi: 10.1186/s40168-017-0249-7

Wéry, N., Galès, A., and Brunet, Y. (2017). "Bioaerosol SOURCES," in Microbiology of Aerosols, eds A.M. Delort and P. Amato (Hoboken, NJ: John Wiley \& Sons, Inc.), 115-135.

Xue, Y., Sun, X., Zhou, P., Liu, R., Liang, F., and Ma, Y. (2003). Gordonia paraffinivorans sp. nov., a hydrocarbon-degrading actinomycete isolated from an oil-producing well. Int. J. Syst. Evol. Microbiol. 53, 1643-1646. doi: 10.1099/ijs.0.02605-0

Yamaguchi, N., Ichijo, T., Sakotani, A., Baba, T., and Nasu, M. (2012). Global dispersion of bacterial cells on Asian dust. Sci. Rep. 2:525. doi: $10.1038 /$ srep 00525

Conflict of Interest Statement: JDR, SJ, KS, KI, and LC are employees of Second Genome, Inc., a sequencing services company that produced the MiSeq data for this study. In exchange for paid services, they assisted with experiment planning and data generation. Reference herein to any specific commercial product, process, or service by trade name, trademark, manufacturer, or otherwise does not necessarily constitute or imply its endorsement, recommendation, or favoring by the United States government. The views and opinions expressed herein do not necessarily state or reflect those of the United States government and shall not be used for advertising or product endorsement purposes.

The remaining authors declare that the research was conducted in the absence of any commercial or financial relationships that could be construed as a potential conflict of interest.

Copyright (ㅇ 2018 Smith, Ravichandar, Jain, Griffin, Yu, Tan, Thissen, Lusby, Nicoll, Shedler, Martinez, Osorio, Lechniak, Choi, Sabino, Iverson, Chan, Jaing and $M c G r a t h$. This is an open-access article distributed under the terms of the Creative Commons Attribution License (CC BY). The use, distribution or reproduction in other forums is permitted, provided the original author(s) and the copyright owner(s) are credited and that the original publication in this journal is cited, in accordance with accepted academic practice. No use, distribution or reproduction is permitted which does not comply with these terms. 